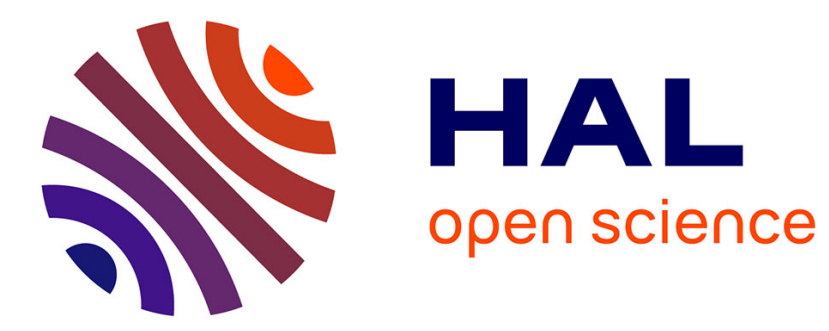

\title{
Assembly via Hydrogen Bonds of Low Molar Mass Compounds into Supramolecular Polymers
}

\author{
Laurent Bouteiller
}

\section{To cite this version:}

Laurent Bouteiller. Assembly via Hydrogen Bonds of Low Molar Mass Compounds into Supramolecular Polymers. Binder, Wolfgang. Hydrogen Bonded Polymers, 207, Springer Berlin Heidelberg, pp.79-112, 2007, 978-3-540-68587-6 978-3-540-68588-3. 10.1007/12_2006_110. hal-01696729

\section{HAL Id: hal-01696729 \\ https://hal.science/hal-01696729}

Submitted on 29 Aug 2020

HAL is a multi-disciplinary open access archive for the deposit and dissemination of scientific research documents, whether they are published or not. The documents may come from teaching and research institutions in France or abroad, or from public or private research centers.
L'archive ouverte pluridisciplinaire HAL, est destinée au dépôt et à la diffusion de documents scientifiques de niveau recherche, publiés ou non, émanant des établissements d'enseignement et de recherche français ou étrangers, des laboratoires publics ou privés. 


\title{
Assembly via hydrogen bonds of low molar mass compounds into supramolecular polymers
}

\author{
LAURENT BOUTEILLER
}

Université Pierre et Marie Curie - Paris 6,

UMR 7610 CNRS - Laboratoire de Chimie des Polymères

4 place Jussieu, 75252 Paris Cedex 05, France

bouteil@ccr.jussieu.fr

Table of contents

1 Introduction

2 Macroscopic properties of HBSPs

$2.1 \quad$ Rheological properties of HBSP solutions

2.1.1 Ureidopyrimidinone (UPy)

2.1.2 Benzene-tricarboxamide (BTC)

2.1.3 Cyclohexane-tricarboxamide (CTC)

2.1.4 Bis-urea

2.1.4.1 Supramolecular structure of bis-urea 3

2.1.4.2 Properties of the thin filament structure

2.1.4.3 Properties of the tubular structure

2.1.5 Oligopeptides

2.2 Material properties of bulk HBSPs

2.2.1 Amorphous glasses

2.2.2 Macroscopic fiber formation

2.2.3 Elastic materials

2.3 Liquid crystallinity

$3 \quad$ Engineering possibilities

3.1 Improving the strength of the association

3.2 Influence of the solvent

3.3 Tuning the ring-chain equilibrium

3.4 Copolymers

3.5 Introducing branches or crosslinks

3.6 Responsiveness induced by external triggers

3.7 Chirality 
3.8 Coupling electro-optical properties

3.9 Polarity of the chain

3.10 Chain stoppers

3.11 Surface grafting

3.12 Covalent capture

$4 \quad$ Molar mass measurement

4.1 Size exclusion chromatography (SEC)

4.2 Light scattering

4.3 Small angle neutron scattering (SANS)

4.4 Viscosimetry

4.5 Vapor pressure osmometry (VPO)

4.6 NMR spectroscopy

4.7 FTIR spectroscopy

$4.8 \quad$ Fluorescence spectroscopy

4.9 Isothermal titration calorimetry (ITC)

$5 \quad$ Conclusions and outlook

Abstract : Supramolecular polymers are linear chains of low molar mass monomers held together by reversible and highly directional non-covalent interactions. In suitable experimental conditions, they can display polymerlike rheological or mechanical properties, because of their macromolecular architecture. However, the fact that non-covalent interactions are involved, means that the assembly can be reversibly broken and can be under thermodynamic equilibrium. This reversibility brings additional features compared to usual polymers, which potentially lead to new properties, such as improved processing, self-healing behavior or stimuli responsiveness. The present chapter focuses first on particular examples where macroscopic properties of HBSPs are clearly demonstrated, and then on the numerous engineering options explored so far to obtain functional materials.

Finally, because the obtained properties depend strongly on the molar mass of the supramolecular polymer in the conditions of use, the last part describes the techniques available to characterize the molar mass of supramolecular polymers.

Key-words : Hydrogen bond, supramolecular polymer, self assembly, rheology, molar mass.

\section{List of Abbreviations}


overlap concentration

CTC

cyclohexane-tricarboxamide

$\mathrm{DP}_{\mathrm{n}}$

number average degree of polymerization

DSC

differential scanning calorimetry

FTIR

fourier transform infrared spectroscopy

HBSP

hydrogen bonded supramolecular polymer

ITC

isothermal titration calorimetry

$\mathrm{M}_{\mathrm{n}}$

number average molar mass

NMR

nuclear magnetic resonance

PDMS

poly(dimethylsiloxane)

SANS

small angle neutron scattering

SEC

size exclusion chromatography

STM

scanning tunneling microscopy

$\mathrm{T}_{\mathrm{g}}$

glass transition temperature

UPy

ureidopyrimidinone

VPO

vapor pressure osmometry

\section{1}

\section{Introduction}

Supramolecular polymers are linear chains of low molar mass monomers held together by reversible and highly directional non-covalent interactions. In suitable experimental conditions, they can display polymer-like rheological or mechanical properties, because of their macromolecular architecture. However, the fact that non-covalent interactions are involved, means that the assembly can be reversibly broken. This reversibility brings additional features compared to usual polymers, which can potentially lead to new properties, such as improved processing, self-healing behavior or stimuli responsiveness.

It is possible to find in the literature early examples describing the formation of hydrogen bonded oligomers from simple monomers such as 4-(thio)pyridone [1, 2] or dialkylureas [3, 4]. However, the concept of supramolecular polymers was really demonstrated in 1990 by Lehn et al., who prepared a liquid crystalline supramolecular polymer by self-assembly of two complementary monomers [5]. Moreover, a decade ago, Meijer et al. described the first supramolecular polymer which formed highly viscous dilute solutions [6], thus proving that it 
is possible to obtain polymer-like rheological properties. Usually, the monomers can be schematized as two (or more) hydrogen bonding moieties linked through a spacer (Fig. 1). According to the topology of the hydrogen bonding groups, three main classes of hydrogen bonded supramolecular polymers (HBSPs) can be found: self-complementary A-A or A-B monomers, or complementary A-A + B-B monomers.

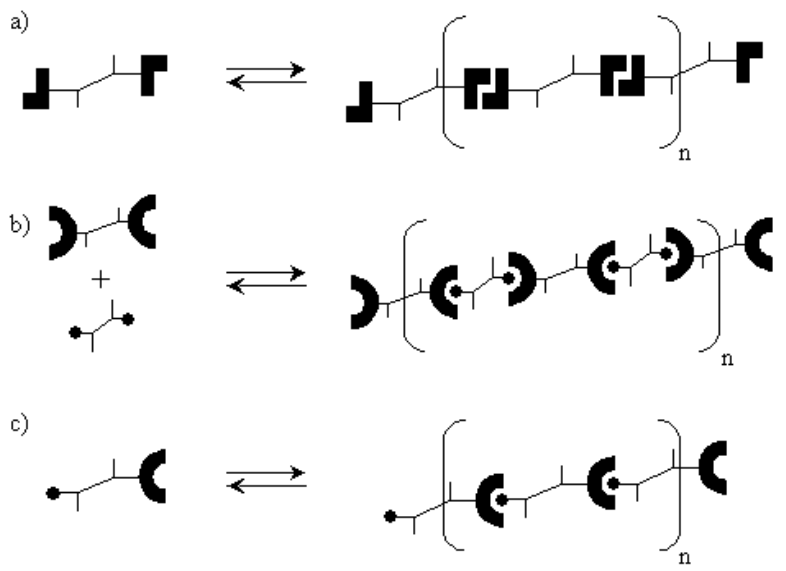

Figure 1 Schematic representation of supramolecular polymers assembled from self-complementary AA (a) or $\mathrm{AB}$ (c) monomers or complementary A-A + B-B (b) monomers.

In some cases, the term "supramolecular polymer" is given a wider meaning, encompassing the huge field at the crossroad between supramolecular chemistry and polymer science [7 10]. In the present chapter, we stick to the more restricted definition mentioned above: we focus on synthetic hydrogen bonded low molar mass compounds which self-assemble to form dynamic polymer-like chains. Thus, the related fields of organogelators [11, 12], nanofibers [13 -15] or crystal engineering $[16,17]$, where crystal packing forces play a major role, are not covered. Likewise, systems where the main driving force for assembly is electrostatic, metal-ligand, hydrophobic or $\pi$-stacking interactions are not systematically included, even if some hydrogen bonding is involved. In fact, HBSPs have been reviewed in the past [18 - 22], but the fast development of this field justifies the present work, which concentrates on the last few years. This chapter focuses first on examples where macroscopic properties of HBSPs are clearly demonstrated, and then on the numerous engineering options explored so far. The last part describes the techniques available to characterize the molar mass of supramolecular polymers. 


\section{Macroscopic properties of HBSPs}

Three kinds of properties are considered here: rheological properties of solutions, properties of bulk materials and liquid crystallinity.

\section{1}

\section{Rheological properties of HBSP solutions}

Depending on the system, different rheological behaviors can be obtained. However, a common requirement is that the association must be very stable for the HBSP to have a significant molar mass in dilute conditions (see $\S 4$ ). The following examples have been chosen because of the large amount of rheological data available, and have been grouped according to the nature of the hydrogen bonding moiety driving the association.

\subsection{1}

\section{Ureidopyrimidinone (UPy)}

The quadruple hydrogen bonding motif of UPy (Fig. 2a) has been designed to form very strong dimers $\left(\mathrm{K}_{\mathrm{dim}}=210^{7} \mathrm{~L} \mathrm{~mol}^{-1}\right.$ in chloroform at $\left.25^{\circ} \mathrm{C}\right)$ [23 - 25]. Consequently, difunctional monomer 1 (Fig. 2b) forms long chains even in dilute solutions: from the value of the equilibrium constant, a degree of polymerization of $\mathrm{DP}_{\mathrm{n}}=1800\left(\mathrm{M}_{\mathrm{n}}=1.310^{6} \mathrm{~g} \mathrm{~mol}^{-1}\right)$ at $0.04 \mathrm{~mol} \mathrm{~L}^{-1}\left(30 \mathrm{~g} \mathrm{~L}^{-1}\right)$ in chloroform can be estimated. It is then not surprising that these solutions show a high viscosity $\left(\eta / \eta_{0}=12\right.$ at a concentration $\left.C=0.04 \mathrm{~mol} \mathrm{~L}^{-1}\right)$ and a high concentration dependence of the viscosity $\left(\eta / \eta_{0} \sim C^{3.7}\right)[6]$. The value of this exponent is in agreement with Cates's model for reversibly breakable chains above the overlap concentration [26, 27]. 
a)<smiles>[R2]c1cc(=O)nc(NC(=O)NN)[nH]1</smiles>

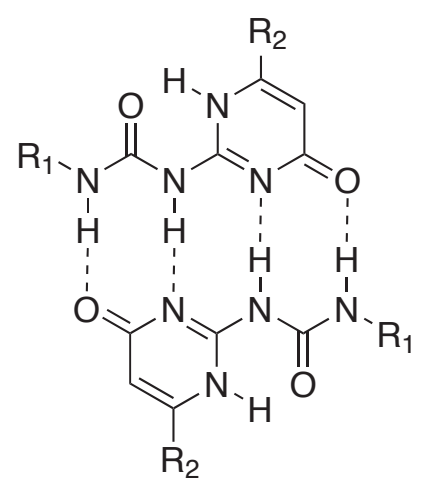

b)

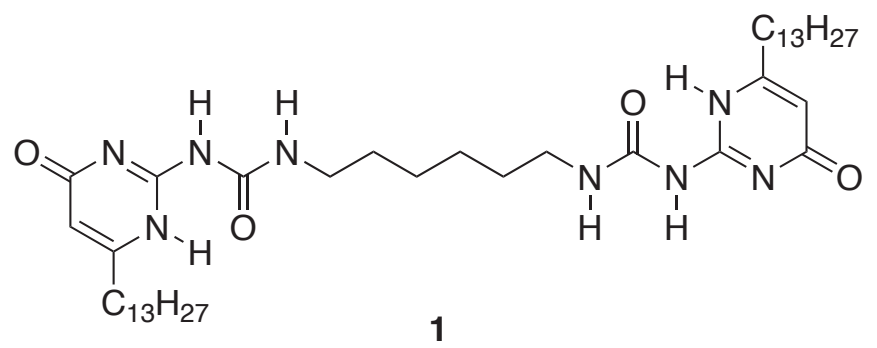

Figure 2 Structure of UPy dimer (a) and monomer 1 (b).

\subsection{2}

\section{Benzene-tricarboxamide (BTC)}

Several BTC derivatives (Fig. 3a) have been shown to form viscoelastic solutions in non polar solvents such as n-alcanes [28]. Based on the crystalline structure of a model compound [29], a supramolecular structure has been proposed. In this proposed structure, monomers are stacked onto each other due to the formation of three hydrogen bonds between the amide groups and to $\pi$-stacking between the aromatic groups (Fig. 3a). Because aromatic and amide groups tend to favor a coplanar conformation, the hydrogen bonds do not lie parallel to the column axis, but are tilted. Thus, the hydrogen bond pattern is believed to be helicoïdal [30, 31]. However, the presence of a significant fraction of free $\mathrm{NH}$ groups detected by FTIR spectroscopy suggests that many defects are present in this helical hydrogen bonding pattern [32].

The consequence of this organization at the molecular level is that BTC solutions in decane are viscoelastic fluids with a nearly perfect Maxwellian behavior [33]. The reason why this BTC system is viscoelastic whereas the previous UPy based system is purely viscous (Newtonian behavior) is probably related to a more rigid backbone and/or to a slower breaking of the chains. 

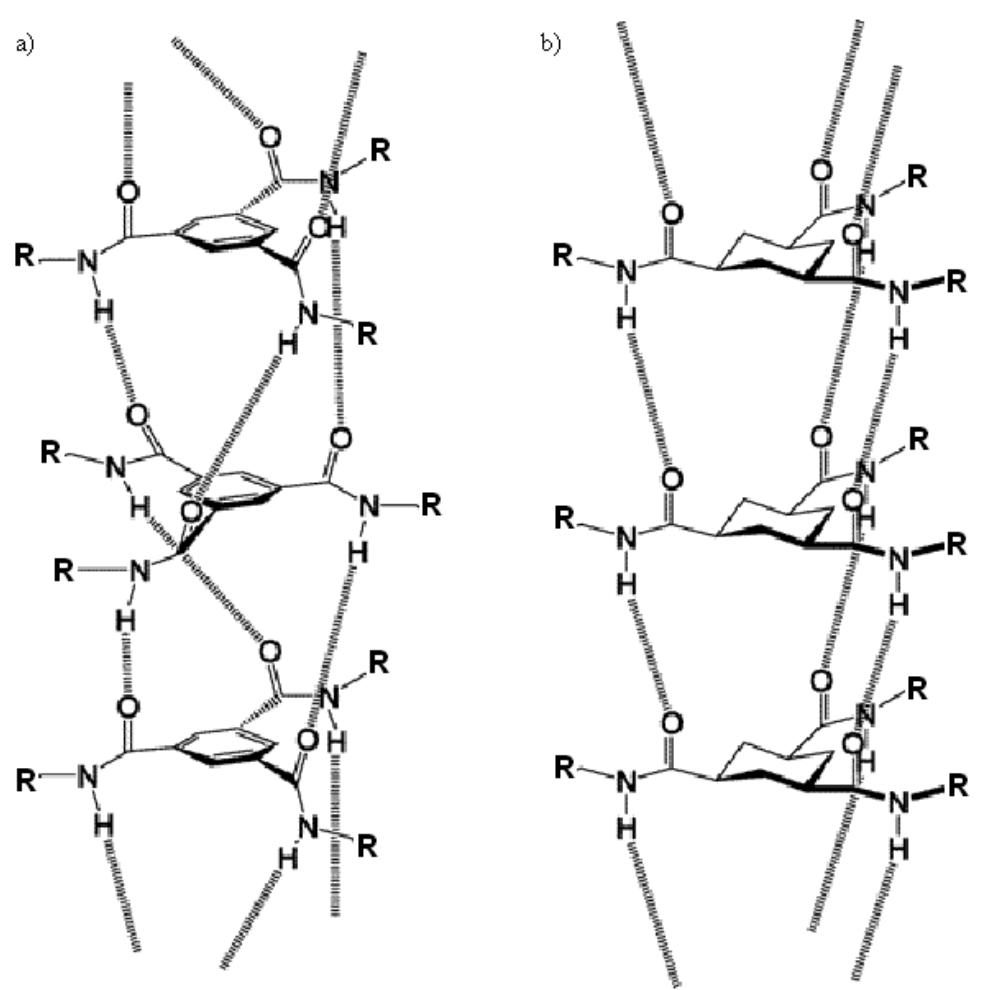

Figure 3 Self-assembled structure of BTC (a) and CTC (b) supramolecular polymers (R = alkyl group). Adapted with permission from [34].

\subsection{3}

\section{Cyclohexane-tricarboxamide (CTC)}

Some related CTC derivatives (Fig. 3b) also form viscoelastic solutions in several non polar solvents [35], but the rheological signature is different from the case of BTC: the frequency dependence of the storage and loss moduli cannot be described by a single relaxation time [36]. Two relaxation times are necessary to adequately fit the data, so that the authors propose a model where the supramolecular polymer would present alternative sequences of rigid rodlike parts and more flexible parts. The increased rigidity of CTC compared to BTC is attributed to its particular hydrogen bonding pattern: because of the lack of $\pi$-stacking interaction and the lack of conjugation between the amides and the cyclohexane ring, the hydrogen bonds are believed to be parallel to the column axis (Fig. 3b). This hypothesis is supported by X-ray crystallography of a model compound [37]. The straight hydrogen 
bonding pattern of CTC may then lead to fewer defects (and thus more rigidity) than the helical pattern of BTC, because no helix reversal defects are expected.

Finally, it is worth mentioning the synthesis of monomer $\mathbf{2}$ bearing two such CTC moieties (Fig. 4) [34]. The straight hydrogen bonding pattern of each CTC moiety is compatible with the formation of six parallel rows of hydrogen bonds, so that compound $\mathbf{2}$ self-associates strongly in chloroform.
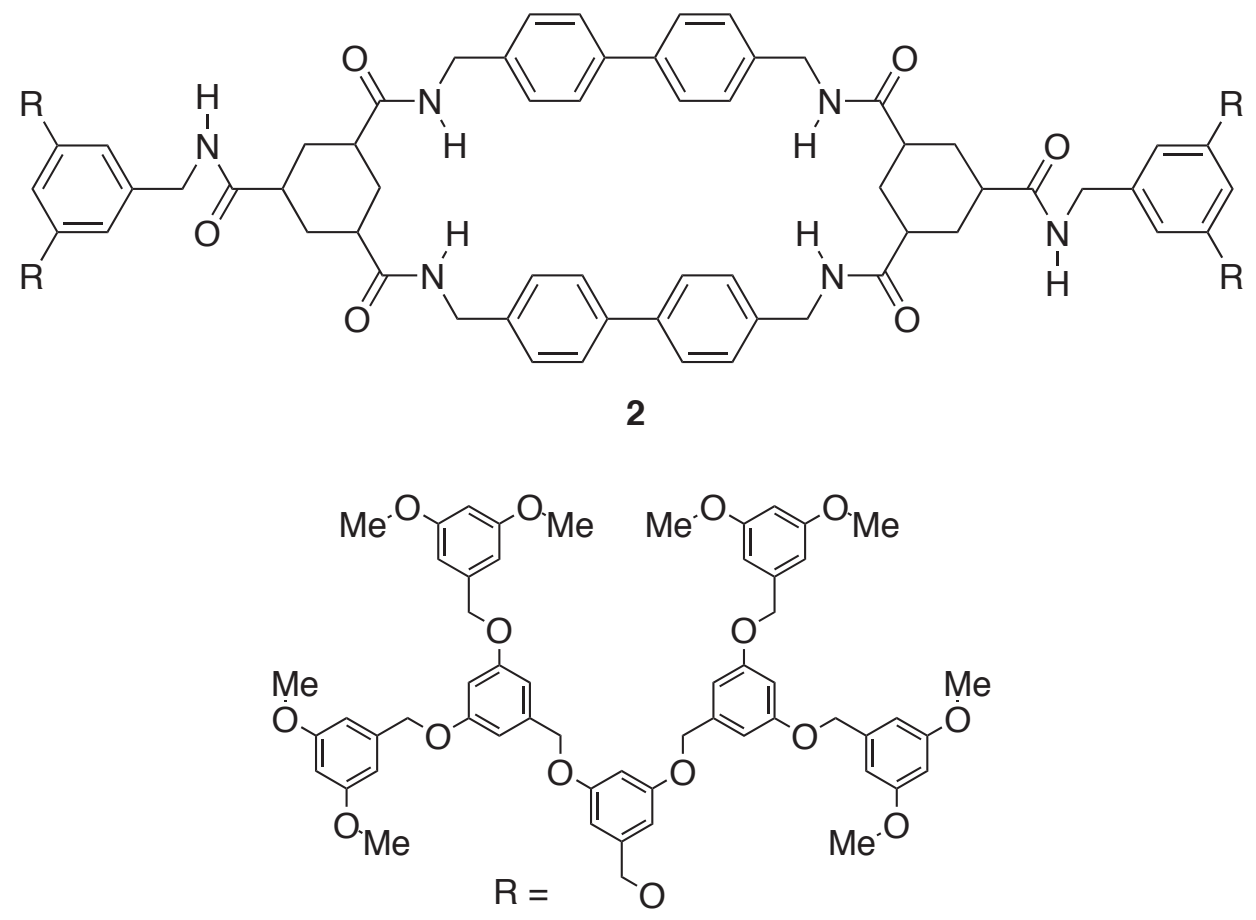

Figure 4 Structure of monomer 2.

\subsection{4}

\section{Bis-urea}

A variety of compounds bearing only two urea functions have been shown to form stable supramolecular architectures, because ureas can form stronger hydrogen bonds than amides. If a parallel or antiparallel orientation of the two ureas is enforced by the spacer connecting them, then long one-dimensional supramolecular assemblies can be expected. Depending on the exact nature of the spacer and the lateral substituents, it is possible to tune both the structure and the dynamic character of the assemblies. With symmetrical spacers and regular substituents, crystallization of the bis-urea is favored, so that organogelators can be obtained $[11,12,38]$. These compounds are dissolved at high temperatures in a particular solvent, but after cooling, highly anisotropic crystalline fibers are formed and entrap the solvent. The 
strong gels obtained are metastable and no dynamic exchange between the fibers occurs at room temperature. However, using an unsymmetrical spacer and/or branched substituents, one can try and destabilize competing crystalline structures and stabilize dynamic HBSPs. Bisureas 3 to 6 with a 2,4-toluene spacer (Fig. 5) indeed form dynamic supramolecular polymers in non polar solvents [39].

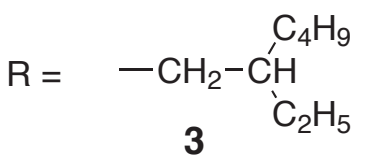<smiles>[R]NC(=O)Nc1ccc(C)c(NC(=O)NC)c1</smiles><smiles>CC(C)CC(C)C(C)C</smiles><smiles>CC(C)CC[P]</smiles>

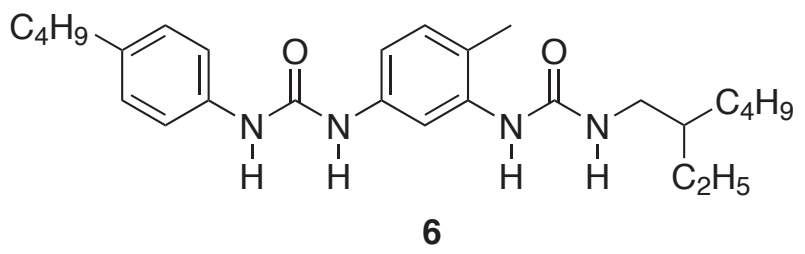

Figure 5 Structure of bis-ureas 3, 4, 5 and 6.

\subsubsection{1}

\section{Supramolecular structure of bis-urea 3}

Fig. 6 shows the pseudo-phase diagram of bis-urea 3 in toluene [40]. It is likely that other (not necessarily dynamic) supramolecular structures exist at lower temperatures or at higher concentrations, but the remarkable feature about this system is that it displays two distinct supramolecular architectures, which are stable over a wide range of concentrations and temperatures, and are in dynamic exchange with the monomer. Of course, the lines on this diagram are not true phase transitions, but limit the domains where each structure is the most abundant. For both supramolecular structures, FTIR spectroscopy can detect no free hydrogen bond. Moreover, small angle neutron scattering (SANS) shows that both structures are long and fibrillar (Fig. 7), the high temperature structure being thinner than the low temperature structure. Based on the SANS derived dimensions, on molecular simulation and on the structure of a monolayer probed by STM (Fig. 8) [41], a ladder-like supramolecular 
arrangement has been proposed for the high temperature, thin filament structure (Fig. 9a) [40]. Similarly, a thick tubular arrangement has been proposed for the low temperature structure (Fig. 9b, 9c) [42]. Such a dynamic tubular structure can be expected to be stable only if the inner cavity is filled with solvent. Consequently, a very strong solvent effect is expected, with solvents of large molecular dimensions destabilizing the tubular structure. This effect was indeed demonstrated (Fig. 10) with a series of aromatic solvents of similar dielectric constants and solvating power [42]. For instance, the transition temperature between the thin and the thick structure is more than $50^{\circ} \mathrm{C}$ lower in bulky 1,3,5-triisopropylbenzene than in toluene.

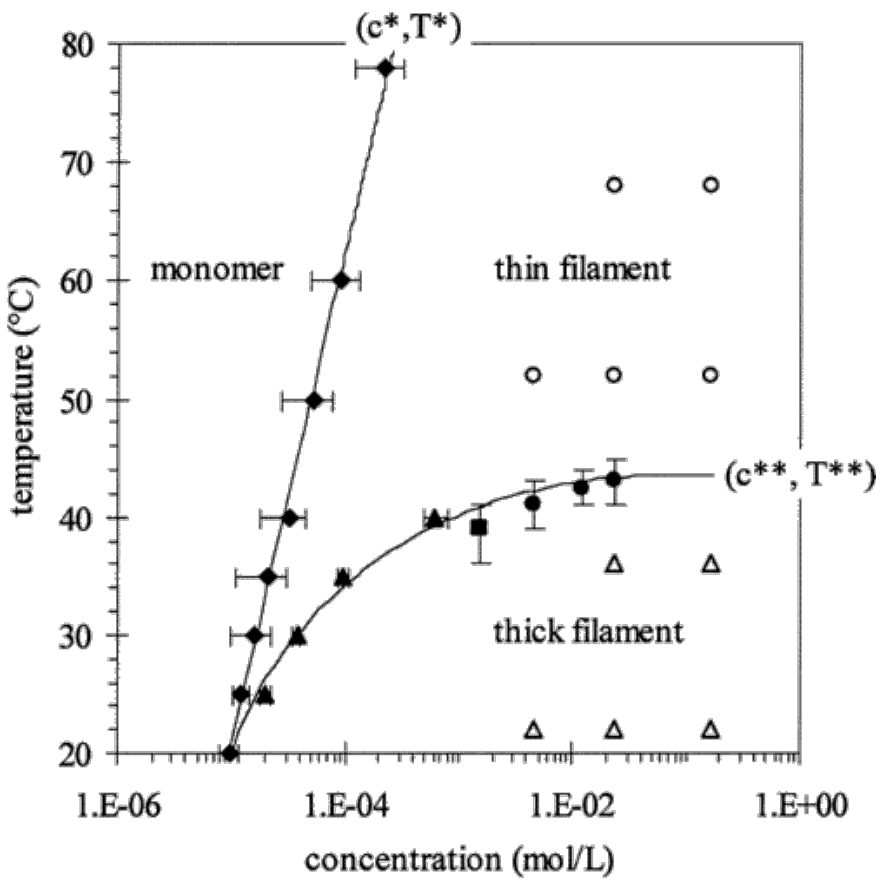

Figure 6 Pseudo-phase diagram for supramolecular polymer 3 in toluene solutions. Transition between monomers and thin supramolecular filaments determined by calorimetry (ITC) ( ). Transition between thin filaments and thick tubes determined by ITC $(\boldsymbol{\Delta})$, viscosimetry $(\boldsymbol{\bullet})$ and FTIR $(\bullet)$. SANS characterization of the thin filaments (o) and thick tubes $(\Delta)$. Reprinted with permission from [40]. 


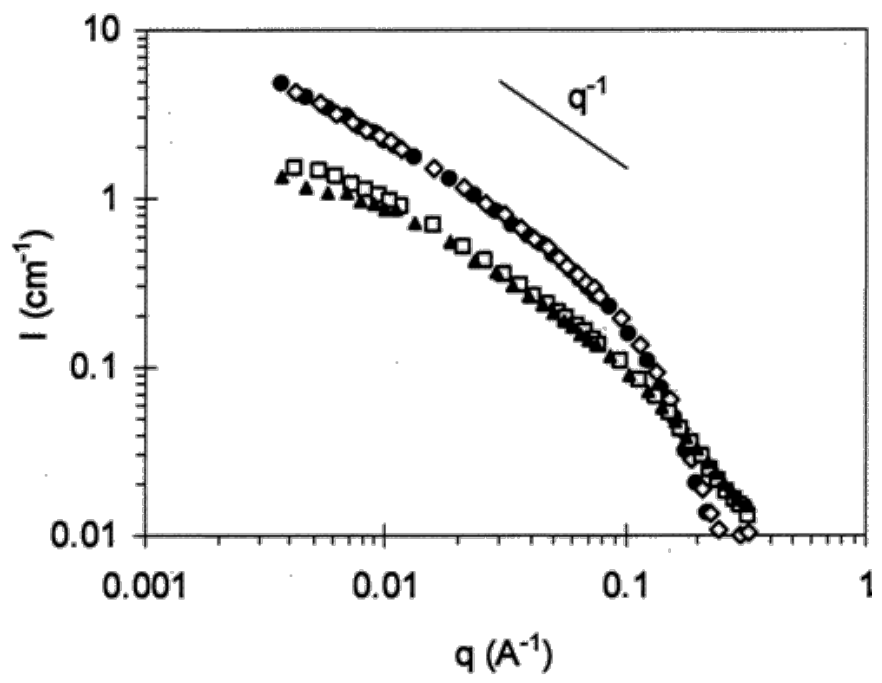

Figure 7 SANS intensity (I) versus momentum transfer (q), for a $22.9 \mathrm{mM}$ solution of supramolecular polymer 3 in $\mathrm{d}_{8}$-toluene at several temperatures $\left(22^{\circ} \mathrm{C}(\bullet) ; 36^{\circ} \mathrm{C}(\diamond) ; 52^{\circ} \mathrm{C}(\square) ; 68^{\circ} \mathrm{C}(\Delta)\right)$. Reprinted with permission from [40].

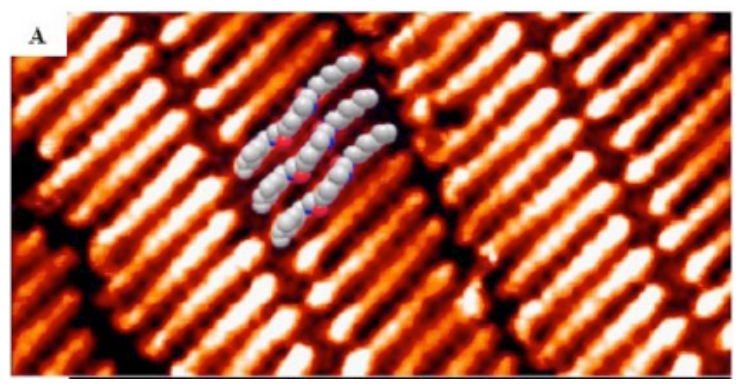

Figure 8 High resolution STM image of a monolayer of supramolecular polymer 3 on $\mathrm{Au}(111)(5 * 10$ $\mathrm{nm}^{2},-0.4 \mathrm{~V}, 1.9 \mathrm{nA}$ ), with insets of a space filling model 3. Reprinted with permission from [41].

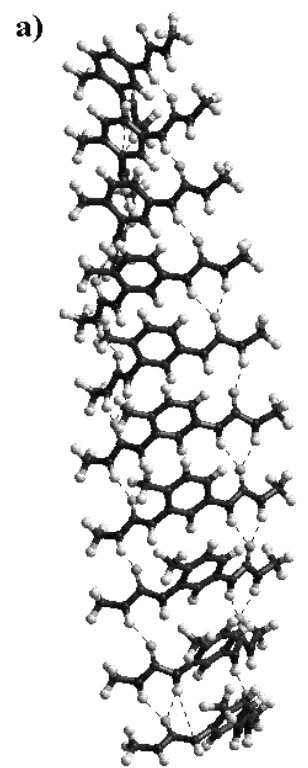

b)

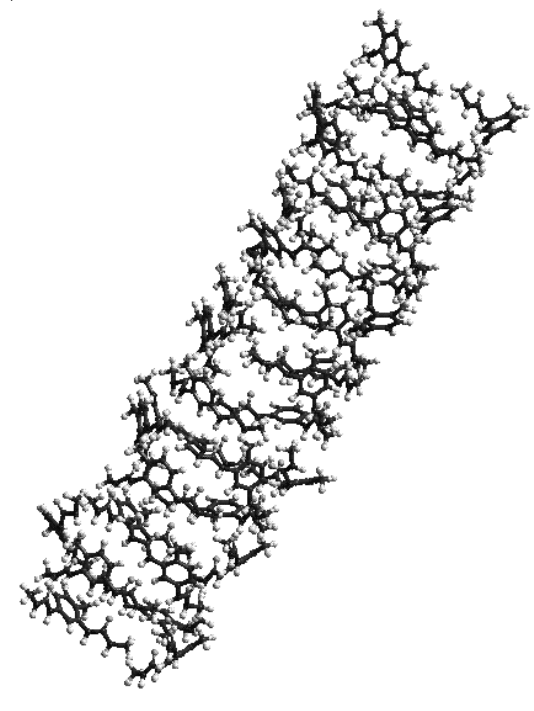

c)

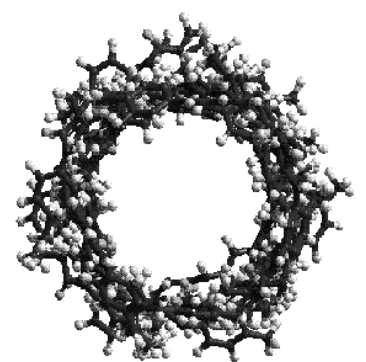

Figure 9 Tentative supramolecular structures proposed for bis-urea 3: thin filament (a) and tubular arrangements: (b) side-view, (c) top-view. 


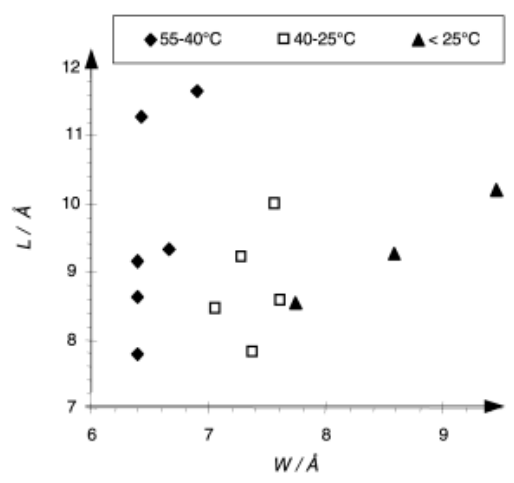

Figure 10 Transition temperature $\left(\mathrm{T}^{* *}\right)$ between the thin filaments and tubes for supramolecular polymer 3 solutions in aromatic solvents, versus length (L) and width (W) of the solvent molecules. The length (L), width (W) and thickness (Th) are defined as the respective dimensions of the smallest rightangled parallelepiped containing the molecule, such that $\mathrm{L}>\mathrm{W}>\mathrm{Th}$. Reprinted with permission from [42].

\subsubsection{2}

\section{Properties of the thin filament structure}

The bis-urea thin filaments can be very long in non polar solvents such as 1,3,5trimethylbenzene. Consequently, these solutions show a high viscosity $\left(\eta / \eta_{0}=8\right.$ at a concentration $\mathrm{C}=0.04 \mathrm{~mol} \mathrm{~L}^{-1}$ and at $\mathrm{T}=20^{\circ} \mathrm{C}$ ) and a high concentration dependence of the viscosity $\left(\eta / \eta_{0} \sim C^{3.5}\right)[43]$. As in the case of UPy based supramolecular polymers, the value of this exponent is in agreement with Cates's model for reversibly breakable polymers [26, 27]. However, the solutions are not viscoelastic, even at concentrations well above the overlap concentration [43]. Consequently, the relaxation of entanglements, probably by chain scission, must be fast $(\tau<0.01 \mathrm{~s})$.

\subsubsection{3}

\section{Properties of the tubular structure}

In contrast, the tubular structure yields strongly viscoelastic solutions in the semi-dilute regime [44, 45]. Fig. 11 shows a Cole-Cole plot for a dodecane solution of $\mathbf{3}\left(\mathrm{C}^{*}=0.1 \mathrm{~g} \mathrm{~L}^{-1}\right)$. Experimental data can be fitted at low frequencies with a Maxwell model, in agreement with the release of entanglements through scission and recombination, but the departure from monoexponentiality at higher frequencies is an indication that the scission-recombination of the supramolecular polymer chains may not be much faster than their reptation. Moreover, a static light scattering study on cyclohexane solutions has shown that the persistence length of the bis-urea tubes is at least $100 \mathrm{~nm}$ [46]. In the framework of Cates theory, the rheological 
characteristics of the bis-urea tubular structure can thus be explained by the presence of semiflexible filaments for which the breaking and reptation times are of the same order of magnitude [47].

In the non-linear regime, the bis-urea solutions display stress-strain curves typical of shearbanding [45].

In summary, the rheological properties of these bis-urea solutions can be switched from a viscoelastic behavior (at low temperatures) to a purely viscous behavior (at high temperatures). Moreover, the transition has been shown to be fast, reversible (without hysteresis) and extremely cooperative: the conversion of tubes into thin filaments occurs within a temperature range of $5^{\circ} \mathrm{C}$ only [40]. This transition can be triggered by temperature, but also by a change in the solvent composition or by a change of the monomer composition.

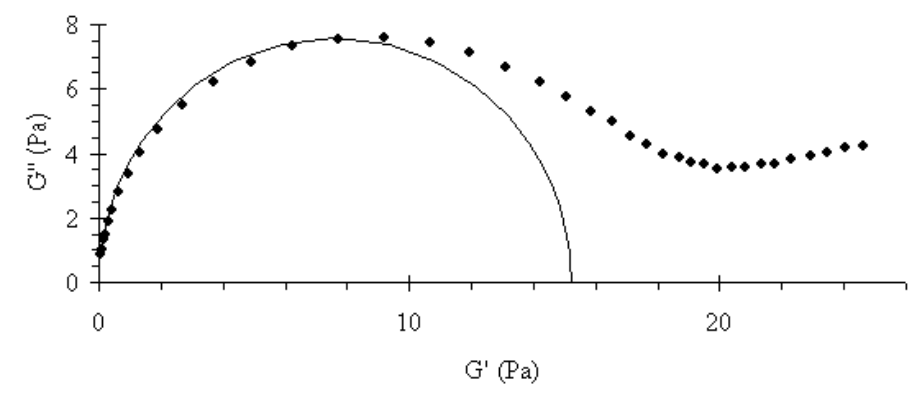

Figure 11 Cole-cole plot for a $7.8 \mathrm{gL}^{-1}$ solution of supramolecular polymer 3 in dodecane, at $25^{\circ} \mathrm{C}$.

\subsection{5}

\section{Oligopeptides}

Carefully designed oligopeptides can self-assemble to form very long $\beta$-sheet tapes (Fig. 12).

Of course, hydrogen bonding is not the only interaction involved, but if the $\beta$-sheets do not further crystallize into irreversible fibers, then these oligopeptides can be considered to be HBSPs, as defined in the Introduction. Boden et al. have indeed prepared several such oligopeptides which form dynamic antiparallel $\beta$-sheet tapes at very low concentrations in alcohols or in water $[48,49]$. At higher concentrations, the tapes dimerize into twisted ribbons due to side-chain interactions, and at still higher concentrations, the ribbons further assemble into fibrils of discrete thickness (Fig. 13) [50, 51]. The different stages of the assembly can be controlled by changing the concentration or the $\mathrm{pH}$. 
Small-strain oscillatory shear experiments show that the $\beta$-sheet tapes form elastic gels over the whole frequency window $\left(10^{-2}-10^{2} \mathrm{rad} \mathrm{s}^{-1}\right)$, implying that the relaxation time of the network is very long [49].

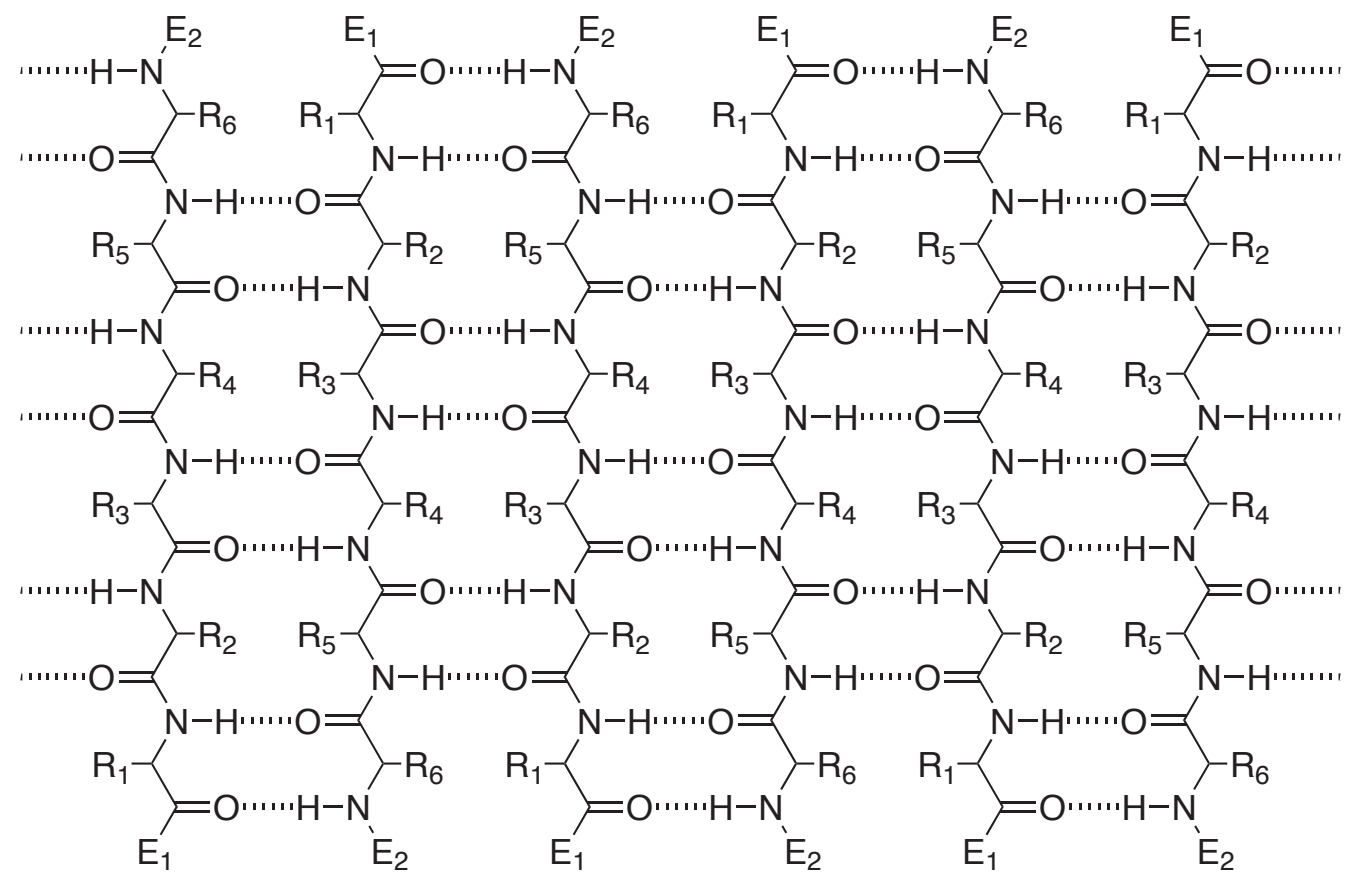

Figure 12 Schematic representation of the self-assembly of a six-residue peptide to form a growing antiparallel $\beta$-sheet tape.

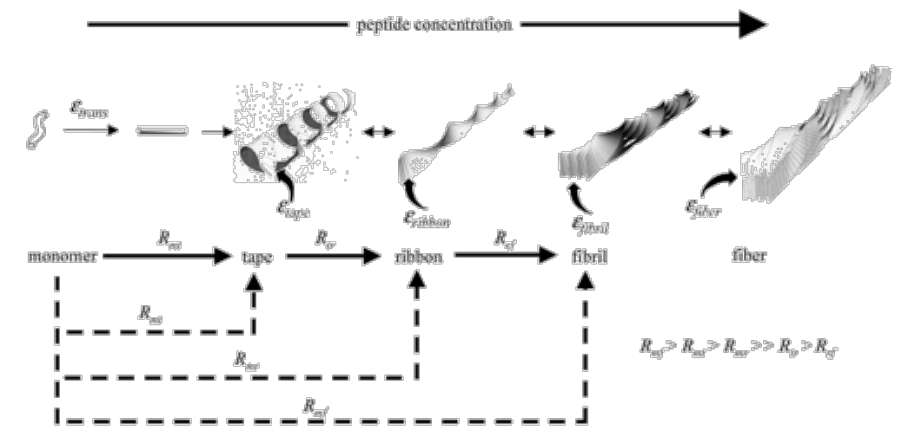

Figure 13 Hierarchical self-assembly of $\beta$-sheet forming peptides. Reprinted with permission from [51].

\section{2}

\section{Material properties of bulk HBSPs}

In the absence of solvent, low molar mass compounds tend to crystallize. Therefore, if polymer-like properties are desired, it is necessary to reduce at least partly their crystallization tendency, through adequate molecular design. The following examples were chosen to illustrate the range of properties currently achieved with HBSPs. 


\subsection{1}

\section{Amorphous glasses}

A few low molar mass compounds form molecular glasses [52], even without strong specific interaction between molecules. However, such compounds are quite rare, and the stability of their glass is usually low. A good way to improve the glass forming ability of low molar mass compounds is to introduce hydrogen bonding groups [53, 54]. For instance, mixing bisphenolA with tetrapyridine 8 (Fig. 14) in a 2:1 ratio yields a stable glass with a glass transition of $31{ }^{\circ} \mathrm{C}$, whereas the pure components are crystalline [53]. Another example is provided by the family of rigid tetrahedral compounds 9 (Fig. 15). If the substituent $\mathrm{R}$ is a butyl group, the compound crystallizes, but if $\mathrm{R}$ is a longer alkyl group, amorphous solids are obtained, probably because the steric hindrance of the alkyl group introduces sufficient disorder [54]. In this case, high $T_{g}$ are obtained $\left(T_{g}=135^{\circ} \mathrm{C}\right.$ for $\mathrm{R}=$ hexyl), due to the rigidity of the compounds. Above the glass transition, high viscosity Newtonian fluids are obtained.<smiles>CC(C)(c1ccc(O)cc1)c1ccc(O)cc1</smiles>

7

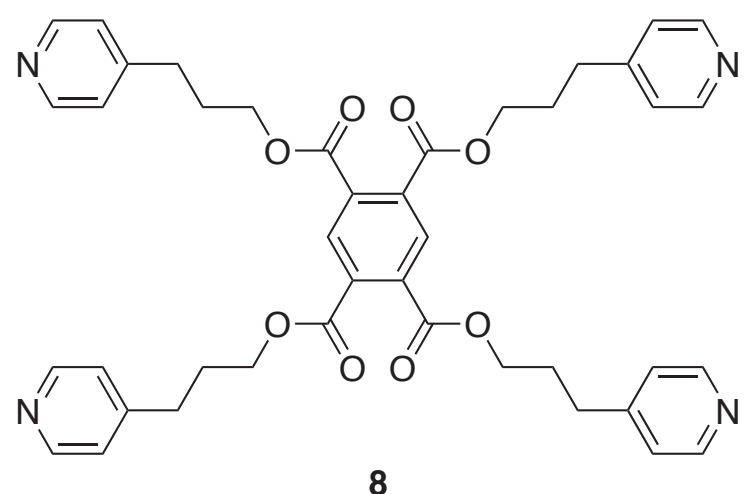

Figure 14 Structure of bisphenol-A 7 and tetrapyridine 8.

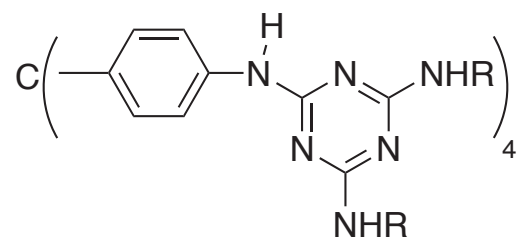

9

Figure $15 \quad$ Structure of tetrahedral monomer 9. 


\subsection{2}

\section{Macroscopic fiber formation}

When hydrogen bonds are established along a preferred direction, it is possible to extrude reasonably strong fibers from the melt [55 - 57] or from a concentrated solution $[58,59,60]$. For example, utilizing the CTC backbone (see $\S 2.1 .3$ ) substituted by branched alkylsilyl sidechains, Araki et al. succeeded in spinning fibers with tensile strengths in the $1 \mathrm{MPa}$ range [57].

\subsection{3}

\section{Elastic materials}

More interestingly, functionalizing oligomers with strongly dimerizing units like UPy (see $\S$ 2.1.1) yields materials with elastic properties similar to high molar mass polymers. This approach is successful even in the case of a very short siloxane oligomer: compound $\mathbf{1 0}$ (Fig. 16) displays a narrow rubbery plateau between its glass transition temperature $\left(\mathrm{T}_{\mathrm{g}}=25^{\circ} \mathrm{C}\right)$ and $70^{\circ} \mathrm{C}$, whereas non hydrogen bonded reference compound $\mathbf{1 0 - B n}$ is a crystalline solid below and a low viscosity liquid above its melting point [61]. With a longer spacer, PDMS 11 shows even better properties. For instance, at low frequencies the complex viscosity of $\mathbf{1 1}$ is 2000 times the viscosity of 11-Bn. Based on DSC and solid-state NMR experiments, it seems that this effect is only due to dimerization of chain-ends, and not to any microcrystalline domains [61]. This approach has been extended to the case of short telechelic poly(ethylene/butylene), polyether, polyester and polycarbonate oligomers [62]. The strong temperature dependence of the viscosity clearly gives a processing advantage to these materials. Moreover, the good thermal stability of the UPy group is to be noted [63]. 

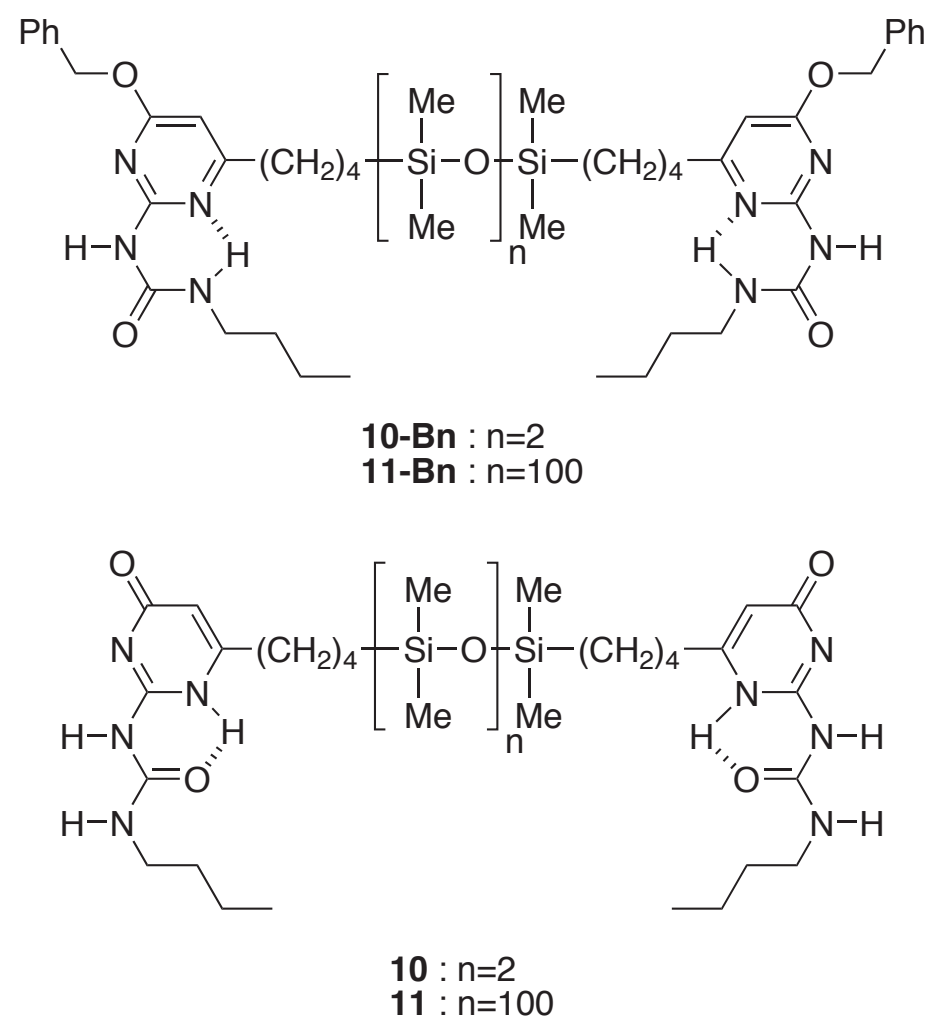

Figure 16 Structure of monomers 10-Bn, 10, 11-Bn and 11.

\section{3}

\section{Liquid crystallinity}

The use of hydrogen bonds in liquid crystalline materials at large is a very active area [64, 65]. In the case of main chain thermotropic liquid crystalline HBSPs, two main approaches have been explored. The first approach is to mix two complementary monomers, usually of the AA + BB type (Fig. 1). The complementary hydrogen bonding units utilized are mainly modified nucleobases [5, 66, 67] and aromatic acid/pyridine couples [55, $68-75]$. In the most successful cases, the pure components are not mesomorphous, but the mixtures are [66,70 72]. At any rate, the stability range of the mesophase is usually increased. The second approach is to use a self-complementary monomer which self-assembles into columns stabilized by amide [76 - 84] or urea [85] bonds along the column axis. Sierra et al. recently proposed a system, which can be considered to be intermediate between the two approaches [86].

Lyotropic HBSPs have also been described [58]. 


\section{Engineering possibilities}

HBSPs self-assemble because the monomers contain specific and directional complementary associating groups. In fact, the structure of a monomer can be understood as made of two independent parts: the associating groups, which can be engineered to optimize the selfassembly process, and the remaining of the molecule (Fig. 1). The latter can be altered nearly at will without compromising the self-assembly, as long as no interfering hydrogen bonding groups are introduced. Consequently, it is possible to tune the properties and to add functionality through chemical design. The following examples illustrate this point.

\section{1}

\section{Improving the strength of the association}

The quantitative treatment of the growth of supramolecular chains is discussed in $\S 4$, but for the present discussion, a qualitative approach is sufficient. Usual associating groups such as acid, amide or urea functions can only form one or two hydrogen bonds and are therefore quite weak. It seems intuitive that the strength of the association increases with the number of hydrogen bonds involved in the assembly. This is indeed a major parameter, but not the only one: based on studies of monofunctional compounds, it has been established that the following parameters cannot be neglected: secondary electrostatic interactions, preorganization of the recognition unit and the presence of competing tautomers [25, 87]. Secondary electrostatic interactions (Fig. 17) arise from the repulsion or attractions between partial charges localized on heteroatoms and hydrogens $[88,89]$. An example of the effect of preorganization is shown on Fig. 18, where the ureidotriazine 12 dimerizes more strongly than the amidotriazine 13, because the intramolecular hydrogen bond in $\mathbf{1 2}$ stabilizes the conformation suitable for association. However, Fig. 19 shows that the gain in preorganization may be offset by the influence of tautomerism, because compounds $\mathbf{1 4}$ and $\mathbf{1 5}$ display similar dimerization efficiencies [90]. The self-association of UPy derivative $\mathbf{1 4}$ is enhanced by the presence of the intramolecular hydrogen bond, but is weakened by the existence of three different tautomeric forms, one of which cannot dimerize [25]. On the other hand, cytosine derivative $\mathbf{1 5}$ is conformationally flexible, but does not undergo tautomeric changes. In fact, it is difficult to rank the influence of these different effects, because any structural change also modifies the overall charge distribution of the recognition unit. Finally, 
obvious steric bulk effects have also been demonstrated in the case of simple dialkylureas [91].

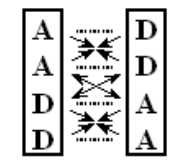

$3.610^{6} \mathrm{~L} \mathrm{~mol}^{-1}$

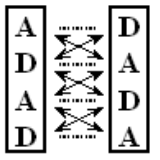

$3.110^{2} \mathrm{~L} \mathrm{~mol}^{-1}$

Figure 17 Self-complementary dimers formed by linear arrays of four hydrogen bonding sites (A: acceptor, D: donor), and their stability constants in $\mathrm{CDCl}_{3}$ as predicted in reference [89]. Attractive and repulsive interactions are indicated by arrows.

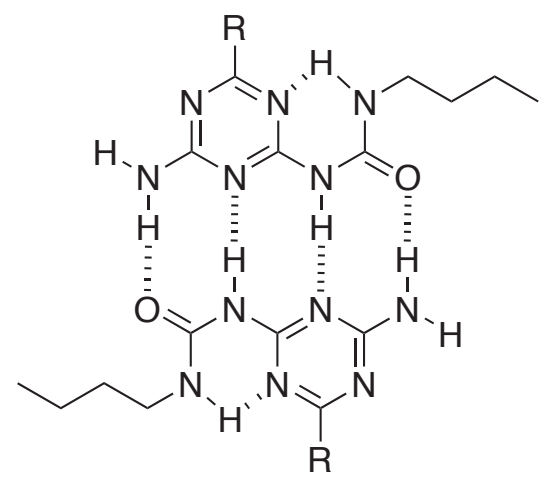

12

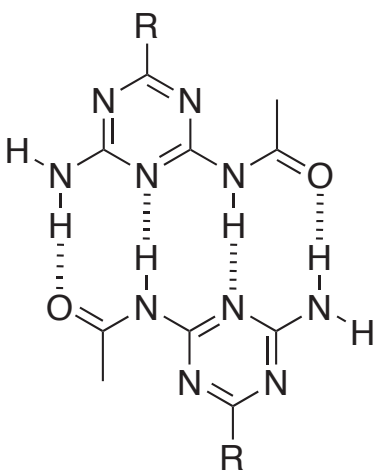

13

$$
\mathrm{K}_{\text {dim }}=210^{4} \mathrm{~L} \mathrm{~mol}^{-1} \quad \mathrm{~K}_{\text {dim }}=530 \mathrm{~L} \mathrm{~mol}^{-1}
$$

Figure 18 Structure of self-complementary compounds 12 and $\mathbf{1 3}$, and their dimerization constants in $\mathrm{CDCl}_{3}[25]$.

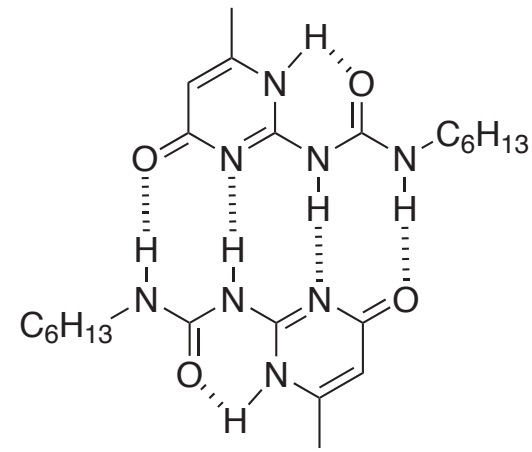

14

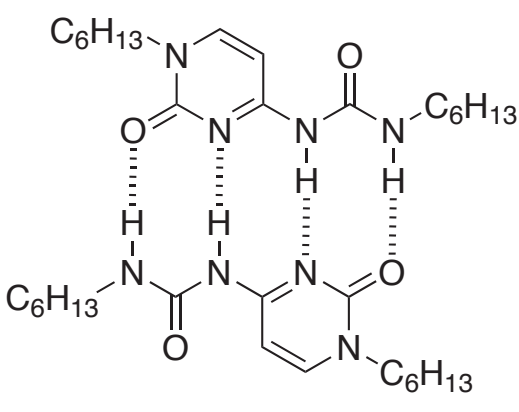

Figure $19 \quad$ Structure of self-complementary compounds $\mathbf{1 4}$ and 15. 


\section{2}

\section{Influence of the solvent}

Because of its electrostatic component, the hydrogen bond is affected by the solvent polarity: the lower the polarity of the solvent, the stronger the association [92]. Quantitatively, this effect can be quite significant for HBSPs: for instance the self-association constant of bis-urea $\mathbf{3}$ is two orders of magnitude larger in toluene than in chloroform [93]. This translates into a ten-fold effect on the degree of polymerization.

In addition to this classical polarity effect, the solvent can have a more subtle influence. In the case of monomer 16 (Fig. 20) hydrogen bonding in chloroform leads to the formation of a usual flexible supramolecular polymer. However, in dodecane the dimerization of the ureidotriazine is reinforced by a solvophobic stacking of the aromatic parts, which yields a columnar architecture [94]. A similar solvophobic effect has been demonstrated with a UPy based monomer [95]. Another possible "side effect" of the nature of the solvent is the occurrence of specific host-guest interactions between the HBSP and the solvent [42, 96, 97]. The case of water is apart due to its biological and environmental relevance. However, designing a HBSP in water is a challenge, because of the polarity and hydrogen bonding ability of water. Nevertheless, several systems based on ureas [98], peptides [48 - 51, 99], heteroaromatic compounds [94, 100 - 103], or oligonucleotides [104 - 107] have been successfully developed by strengthening the hydrogen bond interaction with hydrophobic, $\pi$ stacking and/or electrostatic interactions. 


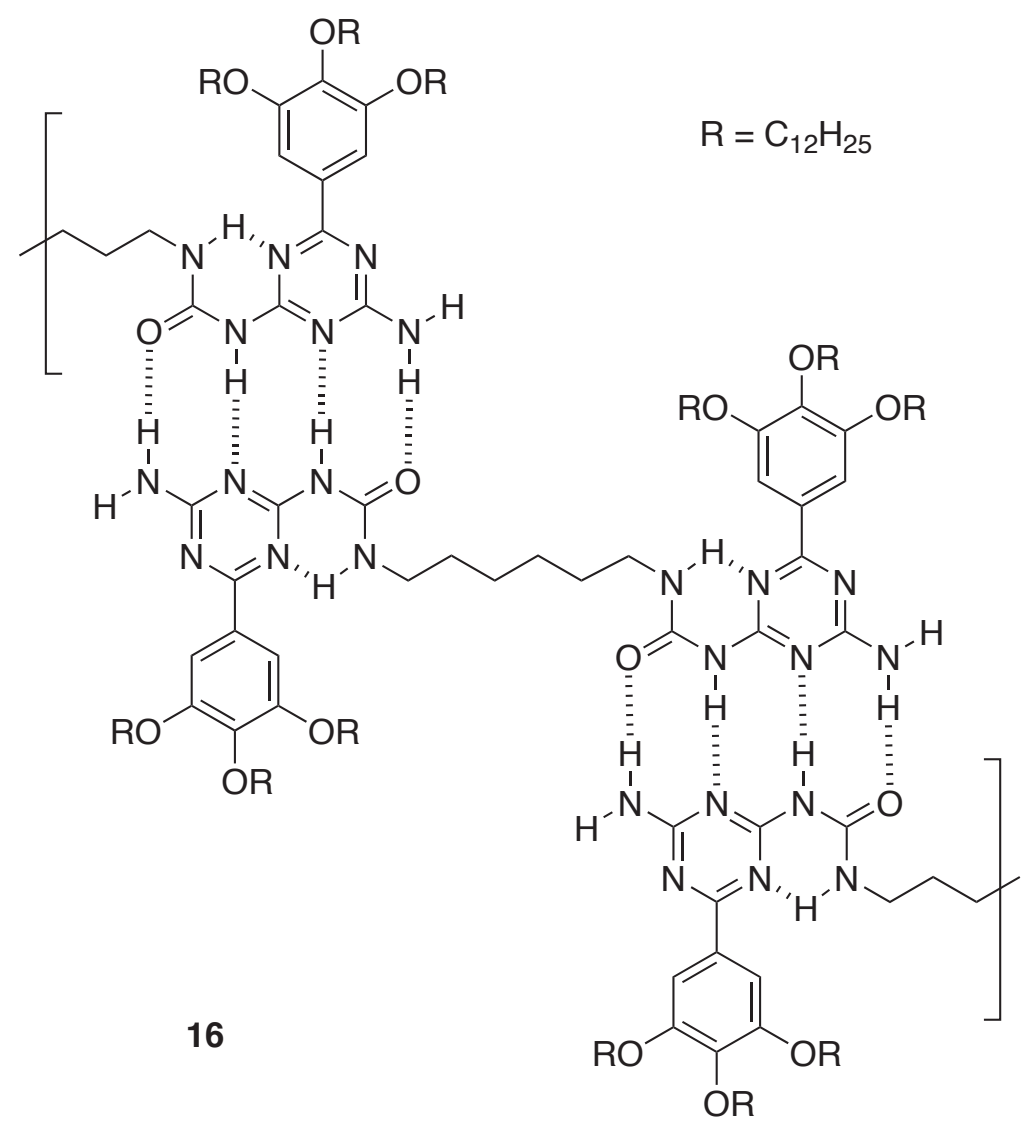

Figure $20 \quad$ Structure of monomer 16.

\section{3}

\section{Tuning the ring-chain equilibrium}

Ring-chain equilibrium in flexible supramolecular polymers has been extensively studied both experimentally $[60,108-113]$ and theoretically $[114,115]$. For strongly associating systems, a threshold concentration is expected below which only cyclic species are present, and above which the amount of cyclic species remains constant. It has been shown that the value of this threshold concentration, and thus the amount of cyclics, is a strong function of the length [108] and the conformation $[109,110,114]$ of the spacer connecting the associating groups. In particular, for very preorganized monomers, it is possible to obtain high yields of cyclic dimers $[116,117]$ or tetramers $[118,119]$. The physicochemical description of this situation has also been reported $[120,121]$. In the case of supramolecular polymers formed by the assembly of two complementary monomers, the cyclic content is minimized if the lengths of the two monomers are mismatched [113]. Generally, a careful choice of the connecting spacer thus makes it possible to design supramolecular polymers with a given cyclisation tendency. 
This in turn influences the properties, mainly because of the lower molar mass of cyclics compared to linear chains.

\section{4}

\section{Copolymers}

In macromolecular science, copolymers are ubiquitous, because their properties can be adjusted by a change in monomer composition. In the case of supramolecular polymers, the preparation of copolymers is particularly straightforward since it requires a simple mixing of different monomers. However, in the vast majority of cases, only statistical copolymers have been reported [30, 31, 40, 72, 73]. To design more elaborate copolymers, some additional information has to be programmed in the structure of the monomers. This has been achieved for alternating HBSPs, where the alternating tendency comes from an improved complementarity [122] or from the non-homopolymerizability of a monomer, either for steric reasons [57] or because of lack of self-complementarity [123]. However, up to now, copolymers with neither statistical nor alternating sequences have only been reported for oligonucleotide-directed assembly $[106,107]$. In this case, the availability of a vast number of orthogonal oligonucleotide recognition groups makes it possible to design copolymers with virtually any sequence.

\section{5}

\section{Introducing branches or crosslinks}

The use of monomers bearing more than two associating groups is a straightforward way to introduce a controlled amount of branches or crosslinks in a supramolecular polymer structure $[6,59,122,124-128]$. The improvement of the mechanical properties can be spectacular. For instance, trifunctional monomer 17 (Fig. 21) forms highly viscous solutions in chloroform, and is a viscoelastic material in the absence of solvent [125]. The reversibly crosslinked network displays a higher plateau modulus than a comparable covalently crosslinked model. This is explained by the fact that the reversibly crosslinked network can reach the thermodynamically most stable conformation, whereas the covalent model, which has been crosslinked in solution and then dried, is kinetically trapped. 


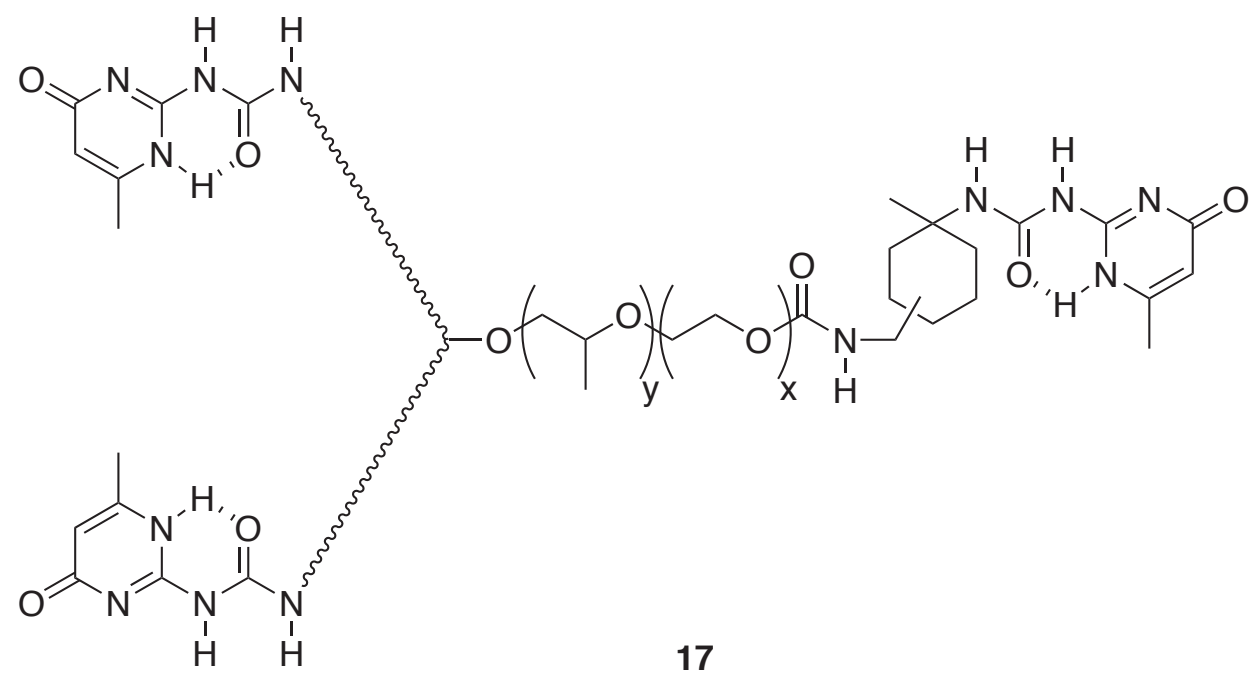

Figure $21 \quad$ Structure of trifunctional monomer 17.

\section{6}

\section{Responsiveness induced by external triggers}

HBSPs are intrinsically more responsive than polymers, due to the temperature and concentration dependence of their molar mass. Moreover, supramolecular polymers with added responsiveness can result from various functional elements introduced within the monomer structure. For instance, light controlled supramolecular polymers have been obtained by incorporating a photoresponsive chromophore between the two self-associating groups of the monomer. Thus, light can trigger a conformational switch [129 - 132] or the formation of a reversible bond within the monomer [133], which then leads to a change of the length of the chains. Alternatively, it is possible to use a chain stopper (see $\S 3.10$ ) bearing a photocleavable protecting group [134]. The deprotection improves the efficiency of the chain stopper, so that the viscosity of the solution decreases upon irradiation.

Another approach is to introduce a suitable chemical function in between the two hydrogen bonding groups of the monomer. For example, this can be an organometallic complex cleaved by addition of a suitable ligand [135, 136]; or a reversible covalent bond [137]; or an ionic interaction controlled by the presence of $\mathrm{CO}_{2}[138-140]$ or $\mathrm{pH}[141]$. 


\section{7}

\section{Chirality}

Monomers decorated with chiral side-chains can induce a transfer of chirality at the supramolecular level. Indeed, several examples show that disk-like molecules, designed to pile up into long reversible columns, form in fact helical columns, driven by the favorable packing of the chiral lateral substituents $[30,32,94,95,100]$. This chiral packing effect is strong enough to induce a chiral amplification: a low amount of chiral monomer mixed with a non chiral monomer can still drive the formation of helical columns.

With a different design, where chirality is directly built in the hydrogen bond pattern (Fig. 22), Aida et al. have demonstrated that it is possible to enforce a homochiral supramolecular polymerization [142]. In this case, a mixture of L and D monomers exclusively forms supramolecular chains of polyL and polyD homopolymers instead of copolymers. In the case of oligopeptides which form dynamic antiparallel $\beta$-sheet tapes $(\S 2.1 .5)$, chirality of the amino-acids is directly responsible for the twisting of the tapes [143, 144]. Moreover, the lateral aggregation of the tapes can lead to the formation of fibrils of discrete thickness, and is in fact controlled by the twisting of the tapes [145 - 147].

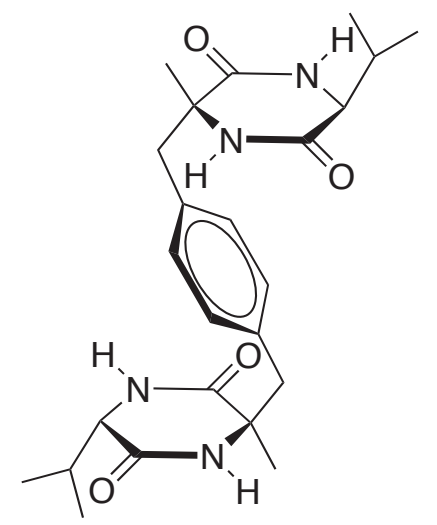

$18 \mathrm{~L}$

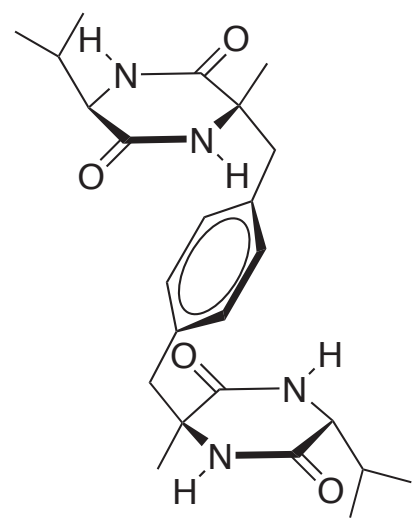

18D

Figure 22 Structure of enantiomeric monomers 18L and 18D.

\section{8}

\section{Coupling electro-optical properties}

Functional supramolecular polymers have be designed by introducing particular chromophores, such as quinacridone [148], perylenes [149 - 151], oligophenylenevinylenes 
$[152,153]$, porphyrins $[118,154-156]$ or merocyanine dyes [157], within the monomer structure. The self-assembly process, by altering the distance between the chromophores, may be coupled to a particular electro-optical property (fluorescence, energy transfer). This could be of interest in the fields of light harvesting and long-range vectorial transport of excitation energy.

\section{9}

\section{Polarity of the chain}

By analogy with the pointed and barbed ends of actin filaments [158], it is worthwhile designing HBSPs with two different extremities. This feature is particularly useful in the context of surface grafting of supramolecular polymers (see § 3.11). Dialkylureas (Fig. 23) are very simple monomers where this breaking of symmetry directly results from the structure of the monomer: one extremity exposes a free carbonyl group to the solvent, while the other extremity presents hydrogen giving groups $[4,91,159]$. More complex bow-shaped monomer 19 (Fig. 24) has also been shown to form directional assemblies [160]. In strongly associated systems like BTC [161] and CTC [162] (see § 2.1.2 and 2.1.3), the symmetry breaking along the chain is responsible for the build up of large macrodipoles that may be useful for electrooptical or electromechanical devices.

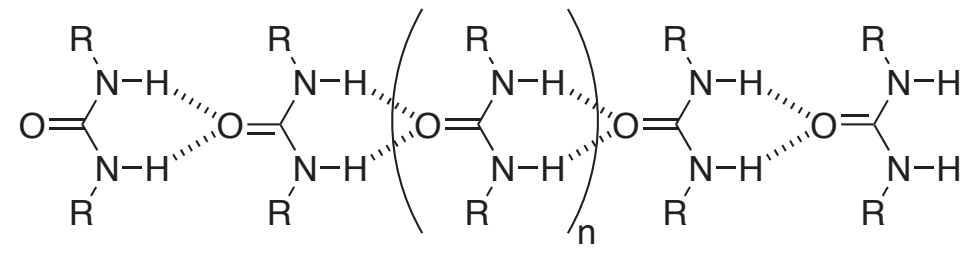

Figure $23 \quad$ Hydrogen bonding pattern of dialkyl ureas.<smiles></smiles>

Figure $24 \quad$ Hydrogen bonding pattern of supramolecular polymer 19. 


\subsection{0}

\section{Chain stoppers}

The fact that supramolecular polymers are assembled by highly directional interactions allows one to design chain stoppers, that is, molecules able to interact specifically with the chain ends of the filaments. For instance, a molecule bearing a single A function is expected to be a chain stopper for an A-A supramolecular polymer. Chain stoppers introduced in varying amounts have often been used simply to reduce the length of the supramolecular chains $[6,97$, $105,124,125,134,155,163,164]$. Indeed, addition of even low amounts of a chain stopper to a supramolecular polymer solution can reduce its viscosity very significantly. More interestingly, chain stoppers can be used to block the concentration dependence of the length of the supramolecular polymer, over a useful concentration range [47, 165, 166]. Indeed, if the monomer concentration and the equilibrium constant of the chain stopper are large enough, nearly all chain ends are occupied by a chain stopper, which means that the length of the filament is inversely proportional to the chain stopper fraction, and independent of the monomer concentration. This feature can be exploited to derive the molar mass and radius of gyration of the stopped supramolecular chains $[165,166]$. Moreover, it means that it becomes possible to independently vary the length and the concentration of the chains, so that scaling exponents for the chain length and concentration dependence of rheological properties can be obtained, and compared to theoretical values, in order to derive some information on chain flexibility and dynamics [47].

Finally, chain stoppers can also be exploited to decorate the chain-ends with particular functional groups or labels [167].

\subsection{1}

\section{Surface grafting}

Arguably one of the most interesting developments of the chain-stopper concept is the use as a surface anchor. Indeed, covalent grafting of a chain-stopper on a surface should yield a supramolecular polymer brush, if the surface is immersed in a supramolecular polymer solution. Such brushes have been realized experimentally with UPy [168] or oligonucleotide $[169,170]$ based monomers. The properties of the brushes (thickness, adhesion) have been studied by AFM, with chain-stopper grafted tips. The conclusion of these preliminary studies is that specific molecular recognition mediates direct bridging and thus adhesion between the 
surface and the tip. Moreover, the average length of the grafted chains seems to be shorter than the chains in the surrounding solution.

Finally, the case of a polar A-B type supramolecular polymer chain with two complementary but different chain-ends is worth considering. If such a system is brought into contact of a surface grafted with an anchoring group bearing only A functions, then a theoretical model shows that the supramolecular brushes formed should exert repulsive forces between approaching surfaces $[171,172]$.

\subsection{2}

\section{Covalent capture}

Covalent capture of supramolecular assemblies can be tricky, because the energy involved in the covalent bond formation is large compared to the stabilizing energy of the self-assembling process [173 - 175]. Consequently, the covalent reaction should be very carefully designed, to avoid disrupting the supramolecular structure. Moreover, in the case of supramolecular polymers, inter-chain crosslinking can be a problem. Up to now, two different approaches have been successful. Meijer et al. have polymerized columnar stacks of BTC derivatives bearing a photopolymerizable sorbate group [176, 177], and Craig et al. have captured oligonucleotide based supramolecular polymers by ligation with a DNA ligase [104]. Sol-gel chemistry has also been used, but in this case, the structure prior to covalent capture has not been characterized, so that it is not known if the final structure was present before the covalent reaction [178 - 180].

\section{4}

\section{Molar mass measurement}

The average molar mass of a supramolecular polymer is a useful information, because polymer-like properties can only be expected if long chains are really formed. Unfortunately, the dynamic nature of supramolecular polymers makes their characterization less straightforward than for usual polymers: the molar mass may change during measurement because of the measuring conditions (for instance in the case of chromatography or mass spectroscopy). Moreover, the knowledge of the molar mass in some particular condition is not really sufficient, because the molar mass changes with the experimental conditions, such as the solvent, the concentration or the temperature. Consequently, it is recommended to characterize the evolution of molar mass in a range of experimental conditions. 
To do so, it is necessary to consider all the possible self-assembled species present in the medium. A convenient way to handle such a complex system is to use a theoretical model involving equilibrium constants between the different species. Determination of the equilibrium constants then makes it possible to compute the average molar mass at any concentration. For example, in the case of a self-complementary monomer $A_{1}$, which is supposed to self-assemble into linear chains $\left(A_{n}\right)$ of degree of polymerization $n$, the relevant theoretical model is described on Fig. 25 [181]. If necessary, the model can be extended to take into account the formation of cyclics $[108,115,119]$.

$$
\begin{aligned}
& \mathrm{A}_{1}+\mathrm{A}_{1} \stackrel{\mathrm{K}_{2}}{\rightleftarrows} \mathrm{A}_{2} \quad\left[\mathrm{~A}_{2}\right]=\mathrm{K}_{2}\left[\mathrm{~A}_{1}\right]\left[\mathrm{A}_{1}\right] \\
& \mathrm{A}_{2}+\mathrm{A}_{1} \stackrel{\mathrm{K}_{3}}{\rightleftarrows} \mathrm{A}_{3} \quad\left[\mathrm{~A}_{3}\right]=\mathrm{K}_{3}\left[\mathrm{~A}_{2}\right]\left[\mathrm{A}_{1}\right] \\
& A_{n-1}+A_{1} \stackrel{K_{n}}{\longleftrightarrow} A_{n} \quad\left[A_{n}\right]=K_{n}\left[A_{n-1}\right]\left[A_{1}\right]
\end{aligned}
$$

Figure 25 Theoretical association model for a self-complementary monomer $\mathrm{A}_{1}$.

Although addition to a growing chain is written as sequential, association may also occur by random association. For example, in addition to adding a monomer to a pentamer, a hexamer may form from two trimers or from a dimer and a tetramer. Since we are interested in the thermodynamic equilibrium state and not in the kinetically most favored pathway or in the mechanism of aggregate formation, the selection of expressions does not affect the final result, as long as all the possible species are included. As described in Fig. 25, this model involves an infinity of unknown parameters $\left(\mathrm{K}_{\mathrm{n}}\right)$. Simplifying assumptions are thus required. The simplest model is the so called isodesmic model, which assumes no chain-length dependence of the equilibrium constants $\left(K_{n}=K\right.$, for $\left.n>1\right)$. In this case, the number average degree of polymerization can be very simply expressed from the equilibrium constant and the total monomer concentration $\mathrm{C}_{0}[182]$.

$$
\mathrm{DP}_{\mathrm{n}}=\frac{1+\sqrt{1+4 \mathrm{KC}_{0}}}{2} \approx \sqrt{\mathrm{KC}_{0}}
$$

A direct information derived from this analysis is that very large equilibrium constants are required if long supramolecular chains are sought. For instance, at a concentration of $\mathrm{C}_{0}=10^{-}$ ${ }^{2} \mathrm{~mol} \mathrm{~L}^{-1}$, a degree of polymerization of 100 is only possible if the equilibrium constant is $\mathrm{K}=$ $10^{6} \mathrm{~L} \mathrm{~mol}^{-1}$.

The isodesmic model has been very successfully used in many cases $[6,108,124,149,150]$. However, steric or electronic effects may be responsible for significant departures from the 
isodesmic model. In particular, anticooperative [183] or cooperative [129, 184 - 186] systems have been described. The case of cooperative systems, where the formation of long chains is favored over dimerization, is most interesting because the concentration dependence of the molar mass is stronger, so that the system is potentially more responsive than an isodesmic system [186].

Let us now focus on the different experimental techniques available to characterize the molar mass of supramolecular polymers.

\section{1}

\section{Size exclusion chromatography (SEC)}

The separation of chains according to their hydrodynamic volume inside SEC columns is accompanied by their dilution. Consequently, the molar mass distribution is shifted toward lower values during the measurement. Usually, the dissociation of hydrogen bonded chains is fast compared to the elution time, so that only qualitative information can be derived [116, $122,142]$. However, if the dissociation is sufficiently slow, it is possible to measure reliable molar mass values $[187,188]$.

\section{2}

\section{Light scattering}

The weight average molar mass of a polymer can be deduced from static light scattering experiments, through the classical Zimm treatment which involves extrapolation to zero concentration and zero angle. In the case of supramolecular polymers, the extrapolation to zero concentration is problematic because of the dynamic character of the chains. Two approaches have been proposed to circumvent this problem. The first consists in measuring the scattered light intensity at a sufficiently low concentration and to neglect the effect of the second virial coefficient [189]. Alternatively, it is possible to evaluate the second virial coefficient by using solutions containing controlled amounts of chain stoppers [165].

\section{3}

\section{Small angle neutron scattering (SANS)}

SANS is a useful technique to derive some information on the structure and the shape of supramolecular polymers [190]. In particular, the length of rigid-rod supramolecular polymers 
can be determined if it is below about $50 \mathrm{~nm}[94,167,191]$. From the length of the rods, the molar mass can easily be deduced.

\section{4}

\section{Viscosimetry}

Molar mass of polymers can be deduced from intrinsic viscosity measurement through a Mark-Houwink calibration curve. This approach can be applied to supramolecular polymers if Mark-Houwink and Huggins parameters are known [192]. However, finding a suitable covalent model to estimate these coefficients is a difficult task.

\section{5}

\section{Vapor pressure osmometry (VPO)}

The measure of the osmotic coefficient by VPO is increasingly used to deduce the molar mass of supramolecular polymers [166, 193 - 196]. However, care must be taken to work at concentrations as low as possible to minimize other contributions than self-association to nonideality [197]. If not, the values obtained may only be considered as orders of magnitudes.

\section{6}

\section{NMR spectroscopy}

Solution NMR spectroscopy is the most widely used technique to determine the equilibrium constant of supramolecular polymers $[23,24,60,124,149,150,159,198]$, either directly or with the help of a monofunctional model compound. In the usual case of a fast exchange between free and hydrogen bonded extremities, the equilibrium constants of a particular association model are derived from the analysis of the evolution of the chemical shift versus concentration (for self-complementary functions) or versus stoechiometry (for complementary functions). Equilibrium constants in the range below $10^{6} \mathrm{M}^{-1}$ are reliably accessible. Estimation of the molar mass of a bulk supramolecular polymer by extrapolation of values determined in solution is always questionable. Therefore, a method based on transverse relaxation measurements of bulk samples was proposed [199]. It takes advantage of the fact that the strength of residual dipolar interactions depends on the molar mass in entangled polymer melts. 


\section{7}

\section{FTIR spectroscopy}

Hydrogen bonding of associative groups is often characterized by a measurable shift of an absorption band. The measure of the intensity of these bands affords the equilibrium constant [91, 108, 186, 200]. However, the use of FTIR spectroscopy is less versatile than NMR spectroscopy because solvent absorption often limits the dilution range accessible.

\section{8}

\section{Fluorescence spectroscopy}

In the case of fluorescent monomers, monitoring the change of fluorescence upon association directly yields the equilibrium constant $[150,183]$. Alternatively, it is possible to label the monomer with a suitable excimer forming chromophore [24] or with a pair of chromophores for fluorescence resonance energy transfer studies [201]. The clear advantage of fluorescence spectroscopy is its high sensitivity enabling the measurement of equilibrium constants as high as $10^{8} \mathrm{~L} \mathrm{~mol}^{-1}$.

\section{9}

\section{Isothermal titration calorimetry (ITC)}

ITC has been used to determine the equilibrium constant of supramolecular polymers formed either from complementary monomers [202] or from self-complementary monomers [93, 165]. In the former case, the A-A monomer solution is injected into the B-B monomer solution. The exchanged heat measured is proportional to the number of hydrogen bonds formed and thus directly related to the equilibrium constant. In the latter case, the selfcomplementary monomer is simply diluted into pure solvent. This time, the exchanged heat measured is proportional to the number of hydrogen bonds broken and related to the selfequilibrium constant. ITC is a very powerful technique because equilibrium constants as high as $10^{9} \mathrm{~L} \mathrm{~mol}^{-1}$ are accessible [203]. Moreover, a single experiment yields the equilibrium constant together with the molar enthalpy of association $\left(\Delta \mathrm{H}_{\mathrm{assoc}}\right)$. 


\section{Conclusions and outlook}

HBSPs thus constitute a very versatile family of compounds with interesting properties, whether in the presence or in the absence of solvents. Because of the reversibility of the interactions involved, HBSPs are under thermodynamic equilibrium. Consequently, their properties can be adjusted beforehand by a careful structural design, but also in-situ by external stimuli. The obtained properties depend strongly on the molar mass of the supramolecular polymer in the conditions of use (solvent, concentration, temperature). Fortunately, several techniques to measure their molar masses are now available. Among the many interesting current developments in this field, the properties of supramolecular polymers at interfaces have been relativelly little explored so far, but seem especially promising. This includes the preparation of supramolecular polymer brushes [168 172], of monolayers for surface nanopatterning [41] or the study of the influence of supramolecular polymers on colloidal stability [164].

\section{References}

1. Beak DC, Covington JB, Smith SG, White JM, Zeigler JM (1980) J. Org. Chem. 45:1354

2. $\quad$ Etter MC, MacDonald JC, Wanke RA (1992) J. Phys. Org. Chem. 5:191

3. Kozlova TV, Zharkov VV (1981) Zh. Prikl. Spektrosk. 35:303

4. Jadzyn J, Stockhausen M, Zywucki B (1987) J. Phys. Chem. 91:754

5. Fouquey C, Lehn J-M, Levelut A-M (1990) Adv. Mater. 2:254

6. Sijbesma RP, Beijer FH, Brunsveld L, Folmer BJB, Hirschberg JHKK, Lange RFM, Lowe JKL, Meijer EW (1997) Science 278:1601

7. Ciferri A (2002) Macromol. Rapid Commun. 23:511

8. Ciferri A (2003) J. Macromol. Sci. C43:271

9. Ciferri A (2005) Supramolecular Polymers, Marcel Dekker, New York

10. Binder W (2005) Monatshefte Chem. 136:1

11. Terech P, Weiss RG (1997) Chem. Rev. 97:3133

12. Terech P, Weiss RG (2005) Molecular Gels: Materials with self-assembled fibrillar networks, Kluwer, Dordrecht

13. Hartgerink JD, Zubarev ER, Stupp SI (2001) Curr. Opin. Solid State Mat. Sci. 5:355

14. Shimizu T (2003) Polym. J. 35:1

15. Pasini D, Kraft A (2004) Curr. Opin. Solid State Mat. Sci. 8:157

16. Desiraju GR (2002) Acc. Chem. Res. 35:565

17. Wuest JD (2005) Chem. Commun. 5830

18. Zimmerman N, Moore JS, Zimmerman SC (1998) Chem. Ind. 604

19. Brunsveld L, Folmer BJB, Meijer EW, Sijbesma RP (2001) Chem. Rev. 101:4071 
21. ten Cate AT, Sijbesma RP (2002) Macromol. Rapid Commun. 23:1094

22. Armstrong G, Buggy M (2005) J. Mater. Sci. 40:547

23. Beijer FH, Sijbesma RP, Kooijman H, Spek AL, Meijer EW (1998) J. Am. Chem. Soc. 120:6761

24. Söntjens SHM, Sijbesma RP, van Genderen MHP, Meijer EW (2000) J. Am. Chem. Soc. 122:7487

25. Sijbesma RP, Meijer EW (2003) Chem. Commun. 5

26. Cates ME (1987) Macromolecules 20:2289

27. Cates ME, Candau SJ (1990) J. Phys.: Condens. Matter 2:6869

28. Hanabusa K, Koto C, Kimura M, Shirai H, Kakehi A. (1997) Chem. Lett. 429

29. Lightfoot MP, Mair FS, Pritchard RG, Warren JE (1999) Chem. Commun. 1945

30. Brunsveld L, Schenning APHJ, Broeren MAC, Janssen HM, Vekemans JAJM, Meijer EW (2000) Chem. Lett. 292

31. van Gorp JJ, Vekemans JAJM, Meijer EW (2002) J. Am. Chem. Soc. 124:14759

32. Ogata D, Shikata T, Hanabusa K (2004) J. Phys. Chem. B 108:15503

33. Shikata T, Ogata D, Hanabusa K (2004) J. Phys. Chem. B 108:508

34. Jang W-D, Aida T (2004) Macromolecules 37:7325

35. Hanabusa K, Kawakami A, Kimura M, Shirai H (1997) Chem. Lett. 191

36. Shikata T, Ogata D, Hanabusa K (2003) Nihon Reoroji Gakkaishi 31:229

37. Fan E, Yang J, Geib SJ, Stoner TC, Hopkins MD, Hamilton AD (1995) J. Chem. Soc., Chem. Commun. 1251

38. van Esch J, Schoonbeek F, de Loos M, Kooijman H, Spek AL, Kellogg RM, Feringa BL (1999) Chem. Eur. J.

\section{$5: 937$}

39. Boileau S, Bouteiller L, Lauprêtre F, Lortie F (2000) New J. Chem. 24:845

40. Bouteiller L, Colombani O, Lortie F, Terech P (2005) J. Am. Chem. Soc. 127:8893

41. Vonau F, Suhr D, Aubel D, Bouteiller L, Reiter G, Simon L (2005) Phys. Rev. Lett. 94:066103

42. Pinault T, Isare B, Bouteiller L (2006) Chem. Phys. Chem. 7:816

43. Ducouret G. private communication

44. Lortie F, Boileau S, Bouteiller L, Chassenieux C, Demé B, Ducouret G, Jalabert M, Lauprêtre F, Terech P (2002) Langmuir 18:7218

45. Ducouret G, Chassenieux C, Martins S, Lequeux F, Bouteiller L (2006) submitted

46. van der Gucht J, Besseling NAM, Knoben W, Bouteiller L, Cohen Stuart MA (2003) Phys. Rev. E 67:051106

47. Knoben W, Besseling NAM, Bouteiller L, Cohen Stuart MA (2005) Phys. Chem. Chem. Phys. 7:2390

48. Aggeli A, Bell M, Boden N, Keen JN, Knowles PF, McLeish TCB, Pitkeathly M, Radford SE (1997) Nature $386: 259$

49. Aggeli A, Bell M, Boden N, Keen JN, McLeish TCB, Nyrkova I, Radford SE, Semenov AN (1997) J. Mater. Chem. 7:1135

50. Aggeli A, Nyrkova I, Bell M, Harding R, Carrick L, McLeish TCB, Semenov AN, Boden N (2001) Proc. Nat. Acad. Sci. USA 98:11857

51. Aggeli A, Bell M, Carrick LM, Fishwick CWG, Harding R, Mawer PJ, Radford SE, Strong AE, Boden N (2003) J. Am. Chem. Soc. 125:9619

52. Alig I, Braun D, Langendorf R, Wirth HO, Voigt M, Wendorff JH (1998) J. Mater. Chem. 8:847

53. Boileau S, Bouteiller L, Foucat E, Lacoudre N (2002) J. Mater. Chem. 12:195

54. Boils D, Perron M-E, Monchamp F, Duval H, Maris T, Wuest JD (2004) Macromolecules 37:7351

55. Lee C-M, Griffin AC (1997) Macromol. Symp. 117:281

56. Araki K, Takasawa R, Yoshikawa I (2001) Chem. Commun. 1826

57. Takasawa R, Murota K, Yoshikawa I, Araki K (2003) Macromol. Rapid Commun. 24:335 
58. Castellano RK, Nuckolls C, Eichhorn SH, Wood MR, Lovinger AJ, Rebek Jr. J (1999) Angew. Chem. Int. Ed. $38: 2603$

59. Castellano RK, Clark R, Craig SL, Nuckolls C, Rebek Jr. J (2000) Proc. Natl. Acad. Sci. USA 97:12418

60. Gibson HW, Yamaguchi N, Jones JW (2003) J. Am. Chem. Soc. 125:3522

61. Hirschberg JHKK, Beijer FH, van Aert HA, Magusin PCMM, Sijbesma RP, Meijer EW (1999) Macromolecules $32: 2696$

62. Folmer BJB, Sijbesma RP, Versteegen RM, van der Rijt JAJ, Meijer EW (2000) Adv. Mater. 12:874

63. Armstrong G, Buggy M (2002) Polym. Int. 51:1219

64. Kato T, Mizoshita N, Kanie K (2001) Macromol. Rapid Commun. 22:797

65. Beginn U (2003) Prog. Polym. Sci. 28:1049

66. Sivakova S, Rowan SJ (2003) Chem. Commun. 2428

67. Sivakova S, Wu J, Campo CJ, Mather PT, Rowan SJ (2006) Chem. Eur. J. 12:446

68. Bladon P, Griffin AC (1993) Macromolecules 26:6604

69. Lee C-M, Jariwala CP, Griffin AC (1994) Polymer 35:4550

70. Kihara H, Kato T, Uryu T (1998) Liq. Cryst. 24:413

71. He C, Donald AM, Griffin AC, Waigh T, Windle AH (1998) J. Polym. Sci. B 36:1617

72. He C, Lee C-M, Griffin AC, Bouteiller L, Lacoudre N, Boileau S, Fouquey C, Lehn J-M (1999) Mol. Cryst. Liq. Cryst. 332:251

73. Xu J, He C, Toh KC, Lu X (2002) Macromolecules 35:8846

74. Rogness DC, Riedel PJ, Sommer JR, Reed DF, Wiegel KN (2006) Liq. Cryst. 33:567

75. Lu X, He C, Griffin AC (2003) Macromolecules 36:5195

76. Malthête J, Levelut A-M, Liébert L (1992) Adv. Mater. 4:37

77. Albouy P-A, Guillon D, Heinrich B, Levelut A-M, Malthête J (1995) J. Phys. II France 5:1617

78. Pucci D, Veber M, Malthête J (1996) Liq. Cryst. 21:153

79. Allouchi H, Cotrait M, Malthête J (2001) Mol. Cryst. Liq. Cryst. 362:101

80. Garcia C, Malthête J (2002) Liq. Cryst. 29:1133

81. Ungar G, Abramic D, Percec V, Heck JA (1996) Liq. Cryst. 21:73

82. Percec V, Ahn C-H, Bera TK, Ungar G, Yeardley DJP (1999) Chem. Eur. J. 5:1070

83. Percec V, Bera TK, Glodde M, Fu Q, Balagurusamy VSK (2003) Chem. Eur. J. 9:921

84. Gearba RI, Lehmann M, Levin J, Ivanov DA, Koch MHJ, Barbera J, Debije MG, Piris J, Geerts YH (2003) Adv. Mater. 15:1614

85. Kishikawa K, Nakahara S, Nishikawa Y, Kohmoto S, Yamamoto M (2005) J. Am. Chem. Soc. 127:2565

86. Barbera J, Puig L, Romero P, Serrano JL, Sierra T (2005) J. Am. Chem. Soc. 127:458

87. Schmuck C, Wienand W (2001) Angew. Chem. Int. Ed. 40:4363

88. Jorgensen WL, Pranata J (1990) J. Am. Chem. Soc. 112:2008

89. Sartorius J, Schneider H-J (1996) Chem. Eur. J. 2:1446

90. Lafitte VGH, Aliev AE, Horton PN, Hursthouse MB, Bala K, Golding P, Hailes HC (2006) J. Am. Chem. Soc. 128:6544

91. Lortie F, Boileau S, Bouteiller L (2003) Chem. Eur. J. 9:3008

92. Williams DH, Gale TF, Bardsley B (1999) J. Chem. Soc., Perkin Trans 21331

93. Arnaud A, Bouteiller L (2004) Langmuir 20:6858

94. Hirschberg JHKK, Brunsveld L, Ramzi A, Vekemans JAJM, Sijbesma RP, Meijer EW (2000) Nature 407:167

95. Hirschberg JHKK, Koevoets RA, Sijbesma RP, Meijer EW (2003) Chem. Eur. J. 9:4222

96. Castellano RK, Rudkevich DM, Rebek Jr. J (1997) Proc. Natl. Acad. Sci. USA 94:7132

97. Castellano RK, Nuckolls C, Rebek Jr. J (2000) Polymer News 25:44 
98. Chebotareva N, Bomans PHH, Frederik PM, Sommerdijk NAJM, Sijbesma RP (2005) Chem. Commun. 4967

99. Ashkenasy N, Horne WS, Ghadiri MR (2006) Small 2:99

100. Brunsveld L, Vekemans JAJM, Hirschberg JHKK, Sijbesma RP, Meijer EW (2002) Proc. Nat. Acad. Sci. USA 99:4977

101. Brunsveld L, Lohmeijer BGG, Vekemans JAJM, Meijer EW (2000) Chem. Commun. 2305

102. Fenniri H, Mathivanan P, Vidale KL, Sherman DM, Hallenga K, Wood KV, Stowell JG (2001) J. Am. Chem. Soc. $123: 3854$

103. Moralez JG, Raez J, Yamazaki T, Motkuri RK, Kovalenko A, Fenniri H (2005) J. Am. Chem. Soc. 127:8307

104. Fogleman EA, Yount WC, Xu J, Craig SL (2002) Angew. Chem. Int. Ed. 41:4026

105. Xu J, Fogleman EA, Craig SL (2004) Macromolecules 37:1863

106. Gothelf KV, Thomsen A, Nielsen M, Clo E, Brown RS (2004) J. Am. Chem. Soc. 126:1044

107. Waybright SM, Singleton CP, Wachter K, Murphy CJ, Bunz UHF (2001) J. Am. Chem. Soc. 123:1828

108. Abed S, Boileau S, Bouteiller L (2000) Macromolecules 33:8479

109. Folmer BJB, Sijbesma RP, Meijer EW (2001) J. Am. Chem. Soc. 123:2093

110. ten Cate AT, Kooijman H, Spek AL, Sijbesma RP, Meijer EW (2004) J. Am. Chem. Soc. 126:3801

111. Söntjens SHM, Sijbesma RP, van Genderen MHP, Meijer EW (2001) Macromolecules 34:3815

112. Scherman OA, Ligthart GBWL, Sijbesma RP, Meijer EW (2006) Angew. Chem. Int. Ed. 45:2072

113. Yamaguchi N, Gibson HW (1999) Chem. Commun. 789

114. Chen C-C, Dormidontova EE (2004) Macromolecules 37:3905

115. Ercolani G, Mandolini L, Mencarelli P, Roelens S (1993) J. Am. Chem. Soc. 115:3901

116. ten Cate AT, Dankers YW, Kooijman H, Spek AL, Sijbesma RP, Meijer EW (2003) J. Am. Chem. Soc. 125:6860

117. Folmer BJB, Sijbesma RP, Kooijman H, Spek AL, Meijer EW (1999) J. Am. Chem. Soc. 121:9001

118. Ohkawa H, Takayama A, Nakajima S, Nishide H (2006) Org. Lett. 8:2225

119. Ercolani G, Ioele M, Monti D (2001) New J. Chem. 25:783

120. Ercolani G (1998) J. Chem. Phys. B 102:5699

121. Ercolani G (2003) J. Chem. Phys. B 107:5052

122. Castellano RK, Rebek Jr. J (1998) J. Am. Chem. Soc. 120:3657

123. Ligthart GBWL, Ohkawa H, Sijbesma RP, Meijer EW (2005) J. Am. Chem. Soc. 127:810

124. Berl V, Schmutz M, Krische MJ, Khoury RG, Lehn J-M (2002) Chem. Eur. J. 8:1227

125. Lange RFM, van Gurp M, Meijer EW (1999) J. Polym. Sci. Part A : Polym. Chem. 37:3657

126. Versteegen RM, van Beek DJM, Sijbesma RP, Vlassopoulos D, Fytas G, Meijer EW (2005) J. Am. Chem. Soc. $127: 13862$

127. Elkins CL, Viswanathan K, Long TE (2006) Macromolecules 39:3132

128. St. Pourcain CB, Griffin AC (1995) Macromolecules 28:4116

129. Lucas NL, van Esch J, Kellogg RM, Feringa BL (2001) Chem. Commun. 759

130. Takeshita M, Hayashi M, Kadota S, Mohammed KH, Yamato T (2005) Chem. Commun. 761

131. Yagai S, Iwashima T, Kishikawa K, Nakahara S, Karatsu T, Kitamura A (2006) Chem. Eur. J. 12:3984

132. de Jong JJD, Lucas NL, Kellogg RM, van Esch JH, Feringa BL (2004) Science 304:278

133. Ikegami M, Ohshiro I, Arai T (2003) Chem. Commun. 1566

134. Folmer BJB, Cavini E, Sijbesma RP, Meijer EW (1998) Chem. Commun. 1847

135. Hofmeier H, El-ghayoury A, Schenning APHJ, Schubert US (2004) Chem. Commun. 318

136. Hofmeier H, Hoogenboom R, Wouters MEL, Schubert US (2005) J. Am. Chem. Soc. 127:2913

137. Kolomiets E, Lehn J-M (2005) Chem. Commun. 1519

138. Xu H, Hampe EM, Rudkevich DM (2003) Chem. Commun. 2828

139. Xu H, Rudkevich DM (2004) Chem. Eur. J. 10:5432 
141. Xu H, Stampp SP, Rudkevich DM (2003) Org. Lett. 5:4583

142. Ishida Y, Aida T (2002) J. Am. Chem. Soc. 124:14017

143. Fishwick CWG, Beevers AJ, Carrick L, Whitehouse CD, Aggeli A, Boden N (2003) Nano Lett. 3:1475

144. Bellesia G, Fedorov MV, Kuznetsov YA, Timoshenko EG (2005) J. Chem. Phys. 122:134901

145. Nyrkova IA, Semenov AN, Aggeli A, Boden N (2000) Eur. Phys. J. B 17:481

146. Nyrkova IA, Semenov AN, Aggeli A, Bell M, Boden N (2000) Eur. Phys. J. B 17:499

147. Bellesia G, Fedorov MV, Timoshenko EG (2006) Physica A, in press

148. Keller U, Müllen K, De Feyter S, De Schryver FC (1996) Adv. Mater. 8:490

149. Würthner F, Thalacker C, Sautter A (1999) Adv. Mater. 11:754

150. Würthner F, Thalacker C, Sautter A, Schärtl W, Ibach W, Hollricher O (2000) Chem. Eur. J. 6:3871

151. Liu Y, Li Y, Jiang L, Gan H, Liu H, Li Y, Zhuang J, Lu F, Zhu D (2004) J. Org. Chem. 69:9049

152. El-ghayoury A, Schenning APHJ, van Hal PA, van Duren JKJ, Janssen RAJ, Meijer EW (2001) Angew. Chem. Int. Ed. 40:3660

153. Varghese R, George SJ, Ajayaghosh A (2005) Chem. Commun. 593

154. Drain CM, Shi X, Milic T, Nifiatis F (2001) Chem. Commun. 287

155. Ercolani G (2001) Chem. Commun. 1416

156. Yamaguchi T, Ishii N, Tashiro K, Aida T (2003) J. Am. Chem. Soc. 125:13934

157. Yagai S, Higashi M, Karatsu T, Karatsu T, Kitamura A (2005) Chem. Mater. 17:4392

158. Korn ED, Carlier M-F, Pantaloni D (1987) Science 238:638

159. Cazacu A, Tong C, van der Lee A, Fyles TM, Barboiu M (2006) J. Am. Chem. Soc. 128:9541

160. Ikeda M, Nobori T, Schmutz M, Lehn J-M (2005) Chem. Eur. J. 11:662

161. Sakamoto A, Ogata D, Shikata T, Urukawa O, Hanabusa K (2006) Polymer 47:956

162. Sakamoto A, Ogata D, Shikata T, Hanabusa K. (2005) Macromolecules 38:8983

163. Yagai S, Iwashima T, Karatsu T, Karatsu T, Kitamura A (2004) Chem. Commun. 1114

164. Knoben W, Besseling NAM, Cohen Stuart MA (2006) Phys. Rev. Lett. 95:in press

165. Lortie F, Boileau S, Bouteiller L, Chassenieux C, Lauprêtre F (2005) Macromolecules 38:5283

166. Knoben W, Besseling NAM, Cohen Stuart MA (2006) Macromolecules 39:2643

167. Hirschberg JHKK, Ramzi A, Sijbesma RP, Meijer EW (2003) Macromolecules 36:1429

168. Zou S, Schönherr H, Vancso GJ (2005) Angew. Chem. Int. Ed. 44:956

169. Kersey FR, Lee G, Marszalek P, Craig SL (2004) J. Am. Chem. Soc. 126:3038

170. Kim J, Liu Y, Ahn SJ, Zauscher S, Karty JM, Yamanaka Y, Craig SL (2005) Adv. Mater. 17:1749

171. van der Gucht J, Besseling NAM, Cohen Stuart MA (2002) J. Am. Chem. Soc. 124:6202

172. van der Gucht J, Besseling NAM, Fleer GJ (2003) J. Chem. Phys. 119:8175

173. Clark TD, Ghadiri MR (1995) J. Am. Chem. Soc. 117:12364

174. Clark TD, Kobayashi K, Ghadiri MR (1999) Chem. Eur. J. 5:782

175. Bassani DM, Darcos V, Mahony S, Desvergne JP (2000) J. Am. Chem. Soc. 122:8795

176. Masuda M, Jonkheijm P, Sijbesma RP, Meijer EW (2003) J. Am. Chem. Soc. 125:15935

177. Wilson AJ, Masuda M, Sijbesma RP, Meijer EW (2005) Angew. Chem. Int. Ed. 44:2275

178. Tang H, Sun J, Zhou X, Fu P, Xie P, Zhang R (2006) Macromol. Chem. Phys. 204:155

179. Moreau JJE, Vellutini L, Wong Chi Man M, Bied C, Bantignies J-L, Dieudonné P, Sauvajol J-L (2001) J. Am. Chem. Soc. 123:7957

180. Moreau JJE, Pichon BP, Wong Chi Man M, Bied C, Pritzkow H, Bantignies J-L, Dieudonné P, Sauvajol J-L (2004) Angew. Chem. Int. Ed. 43:203

181. Martin RB (1996) Chem. Rev. 96:3043 
182. Here $\mathrm{K}$ is defined as the equilibrium constant between two difunctional monomers. Alternatively, if the equilibrium constant between two functions ( $\mathrm{K}^{\prime}$ ) is considered (as in the example in $\S 2.1 .1$ ), then one should slightly modify the relationship, because $\mathrm{K}=4 \mathrm{~K}$ '.

183. Arnaud A, Belleney J, Boué F, Bouteiller L, Carrot G, Wintgens V (2004) Angew. Chem. Int. Ed. 43:1718

184. Oosawa F, Kasai M (1962) J. Mol. Biol. 4:10

185. Oosawa F, Higashi S (1967) Prog. Theor. Biol. 1:79

186. Simic V, Bouteiller L, Jalabert M (2003) J. Am. Chem. Soc. 125:13148

187. Ogawa K, Kobuke Y (2000) Angew. Chem. Int. Ed. 39:4070

188. Paulusse JMJ, Sijbesma RP (2003) Chem. Commun. 1494

189. Toupance T, Benoit H, Sarazin D, Simon J (1997) J. Am. Chem. Soc. 119:9191

190. Kolomiets E, Buhler E, Candau SJ, Lehn J-M (2006) Macromolecules 39:1173

191. Lopez D, Guenet J-M (2001) Macromolecules 34:1076

192. Abed S, Boileau S, Bouteiller L (2001) Polymer 42:8613

193. Shetty AS, Zhang J, Moore JS (1996) J. Am. Chem. Soc. 118:1019

194. Tobe Y, Utsumi N, Kawabata K, Nagano A, Adachi K, Araki S, Sonoda M, Hirose K, Naemura K (2002) J. Am. Chem. Soc. 124:5350

195. Hasegawa Y, Miyauchi M, Takashima Y, Yamaguchi H, Harada A (2005) Macromolecules 38:3724

196. Stoncius S, Orentas E, Butkus E, Ohrström L, Wendt OF, Wärnmark K (2006) J. Am. Chem. Soc. 128:8272

197. Sugawara N, Stevens ES, Bonora GM, Toniolo C (1980) J. Am. Chem. Soc. 102:7044

198. Cantrill SJ, Youn GJ, Stoddart JF (2001) J. Org. Chem. 66:6857

199. Duweltz D, Lauprêtre F, Abed S, Bouteiller L, Boileau S (2003) Polymer 44:2295

200. Colombani O, Bouteiller L (2004) New J. Chem. 28:1373

201. Castellano RK, Craig SL, Nuckolls C, Rebek Jr. J (2000) J. Am. Chem. Soc. 122:7876

202. Tellini VHS, Jover A, Garcia JC, Galantini L, Meijide F, Tato JV (2006) J. Am. Chem. Soc. 128:5728

203. Zeng H, Miller RS, Flowers RA, Gong B (2000) J. Am. Chem. Soc. 122:2635 
Figure legends

Figure 1 Schematic representation of supramolecular polymers assembled from self-complementary AA (a) or $\mathrm{AB}$ (c) monomers or complementary A-A + B-B (b) monomers.

Figure 2 Structure of UPy dimer (a) and monomer 1 (b).

Figure 3 Self-assembled structure of BTC (a) and CTC (b) supramolecular polymers (R = alkyl group). Adapted with permission from [34].

Figure $4 \quad$ Structure of monomer 2.

Figure 5 Structure of bis-ureas 3, 4, 5 and 6.

Figure 6 Pseudo-phase diagram for supramolecular polymer 3 in toluene solutions. Transition between monomers and thin supramolecular filaments determined by calorimetry (ITC) ( $\bullet$ ). Transition between thin filaments and thick tubes determined by ITC $(\boldsymbol{\Delta})$, viscosimetry $(\boldsymbol{\bullet})$ and FTIR $(\bullet)$. SANS characterization of the thin filaments (o) and thick tubes $(\Delta)$. Reprinted with permission from [40].

Figure 7 SANS intensity (I) versus momentum transfer (q), for a $22.9 \mathrm{mM}$ solution of supramolecular polymer 3 in $\mathrm{d}_{8}$-toluene at several temperatures $\left(22^{\circ} \mathrm{C}(\bullet) ; 36^{\circ} \mathrm{C}(\diamond) ; 52^{\circ} \mathrm{C}(\square) ; 68^{\circ} \mathrm{C}(\boldsymbol{\Delta})\right)$. Reprinted with permission from [40].

Figure 8 High resolution STM image of a monolayer of supramolecular polymer 3 on $\mathrm{Au}(111)(5 * 10$ $\mathrm{nm}^{2},-0.4 \mathrm{~V}, 1.9 \mathrm{nA}$ ), with insets of a space filling model 3. Reprinted with permission from [41].

Figure 9 Tentative supramolecular structures proposed for bis-urea 3: thin filament (a) and tubular arrangements: (b) side-view, (c) top-view.

Figure 10 Transition temperature $\left(\mathrm{T}^{* *}\right)$ between the thin filaments and tubes for supramolecular polymer 3 solutions in aromatic solvents, versus length (L) and width (W) of the solvent molecules. The length (L), width (W) and thickness (Th) are defined as the respective dimensions of the smallest rightangled parallelepiped containing the molecule, such that $\mathrm{L}>\mathrm{W}>\mathrm{Th}$. Reprinted with permission from [42].

Figure 11 Cole-cole plot for a $7.8 \mathrm{gL}^{-1}$ solution of supramolecular polymer 3 in dodecane, at $25^{\circ} \mathrm{C}$.

Figure 12 Schematic representation of the self-assembly of a six-residue peptide to form a growing antiparallel $\beta$-sheet tape. 
Figure $13 \quad$ Hierarchical self-assembly of $\beta$-sheet forming peptides. Reprinted with permission from [51].

Figure 14 Structure of bisphenol-A 7 and tetrapyridine 8.

Figure $15 \quad$ Structure of tetrahedral monomer 9.

Figure $16 \quad$ Structure of monomers 10-Bn, 10, 11-Bn and 11.

Figure 17 Self-complementary dimers formed by linear arrays of four hydrogen bonding sites (A:

acceptor, D: donor), and their stability constants in $\mathrm{CDCl}_{3}$ as predicted in reference [89]. Attractive and repulsive interactions are indicated by arrows.

Figure 18 Structure of self-complementary compounds 12 and 13, and their dimerization constants in $\mathrm{CDCl}_{3}[25]$.

Figure $19 \quad$ Structure of self-complementary compounds $\mathbf{1 4}$ and $\mathbf{1 5 .}$

Figure $20 \quad$ Structure of monomer 16.

Figure $21 \quad$ Structure of trifunctional monomer 17.

Figure 22 Structure of enantiomeric monomers 18L and 18D.

Figure $23 \quad$ Hydrogen bonding pattern of dialkyl ureas.

Figure $24 \quad$ Hydrogen bonding pattern of supramolecular polymer 19.

Figure 25 Theoretical association model for a self-complementary monomer $\mathrm{A}_{1}$. 